\title{
In-Space Propulsion Technologies for Robotic Exploration of the Solar System
}

\author{
Les Johnson ${ }^{*}$ and Rae Ann Meyer. ${ }^{\dagger}$ \\ NASA George C. Marshall Space Flight Center, Alabama 35812 \\ Kyle Frame \\ Gray Research, Inc., Huntsville, AL 35806
}

\begin{abstract}
Supporting NASA's Science Mission Directorate, the In-Space Propulsion Technology Program is developing the next generation of space propulsion technologies for robotic, deep-space exploration. Recent technological advancements and demonstrations of key, high-payoff propulsion technologies have been achieved and will be described. Technologies under development and test include aerocapture, solar electric propulsion, solar sail propulsion, and advanced chemical propulsion.
\end{abstract}

\section{Introduction}

$\mathrm{T}$ HE In-Space Propulsion Technology (ISPT) Program is in its fifth year and significant strides have been made in the advancement of key transportation technologies that will enable or enhance future robotic science and deep space exploration missions. At the program's inception, a set of technology investment priorities were established using an NASA-wide prioritization process ${ }^{1}$ and, for the most part, these priorities have changed little thus allowing a consistent framework in which to fund and manage technology development. Technologies in the portfolio include aerocapture, advanced chemical propulsion, solar electric propulsion and solar sail propulsion.

\section{Aerocapture}

Aerocapture technology uses the exchange of momentum between a spacecraft and an atmosphere to achieve thrust, in this case a decelerating thrust, leading to orbit capture. This technique is very attractive since it permits a spacecraft to be launched from Earth at higher velocities, thus providing a shorter overall trip time. At the destination, the velocity is reduced by aerodynamic drag within the atmosphere. Without aerocapture, a substantial propulsion system would be needed on the spacecraft to perform the same reduction of velocity. This could cause reductions in the science payload delivered to the destination, increases in the size of the launch vehicle (to carry the additional fuel required for planetary capture) or could simply make the mission impossible due to additional propulsion requirements.

Figure 1 illustrates the potential mission-level mass savings resulting from the use of aerocapture at several solar system destinations ${ }^{2}$.

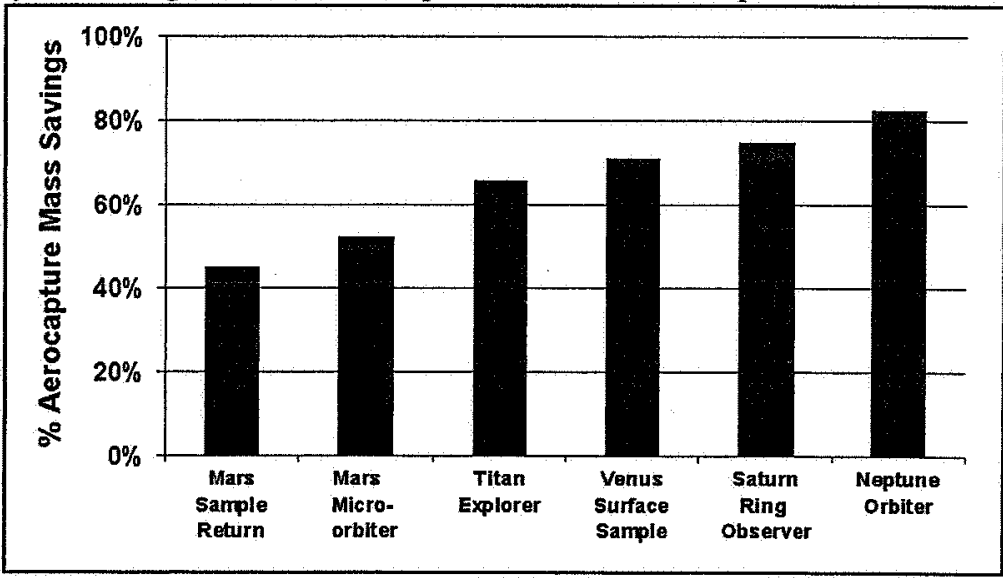

\footnotetext{
* Manager, Science Programs \& Projects Office, VP50, Member, AIAA.

${ }^{\dagger}$ Manger, In-Space Transportation Program Office, VP51, Member, AIAA.

₹ Program Integration, In-Space Propulsion Transportation Office, VP51, Member, AIAA. 
The requirement to slow down a spacecraft non-propulsively can be

achieved in two ways. The craft can be enveloped by a structure with heat shielding applied to the external surfaces. Another option is for the vehicle to deploy an aerocapture inflatable deceleration system as an inflatable ballute -- a combination parachute and balloon made of thin, durable material.

\section{A. Aerocapture Development Approach}

Four different technology concepts are under consideration or development for aerocapture use: 1) a blunt body, rigid aeroshell, 2) a slender body, rigid aeroshell, 3) trailing ballutes, and 4) attached ballutes.

The blunt body, rigid aeroshell system encases a spacecraft in a protective shell. This shell provides an aerodynamic control surface and a means of protection from the high heating experienced during high-speed atmospheric flight. Once a space vehicle is captured into a planet's orbit, the aeroshell is jettisoned ${ }^{3}$.

The slender body configuration looks much like an elongated capsule, with a hard shell surrounding the spacecraft. The design could provide increased volume in the interior of the spacecraft when compared to the blunt body design, allowing for improved packaging of larger crafts. Because of its slender body shape, the system also could provide increased tolerance for navigational and atmospheric uncertainties.

The trailing ballute features an inflated toroidal volume that is much larger than the spacecraft it is 'trailing', much like a parachute, to slow the vehicle down. The trailing ballute design allows for easy detachment and minimizes interference with the spacecraft's operation. The ballute itself is made of a lightweight, thin-film material. $^{4}$

The attached forebody ballute looks much like the aeroshell or blunt body. It is often referred to as a hybrid system, with a rigid foreshell and an inflated, attached ballute extending from either the front or back of the spacecraft. ${ }^{5}$ The inflatable, attached ballute concept extends from a rigid nosecap and works much like a parachute, providing a large surface area to slow the spacecraft down to allow for an aerocapture maneuver to occur. As the spacecraft approaches a planet's atmosphere, the ballute is inflated and then jettisoned once the craft is captured into orbit. $^{6}$

\section{B. Aerocapture Technology Status}

Aerocapture has never been flight tested. Relevant experience, however, exists from ablative entry capsules, including the recent Stardust mission, a comet sample return mission to comet Wild 2, that provides an opportunity for scientists to evaluate the re-entered aeroshell and its thermal protection system (TPS). Ablative entry technologies have been used throughout the history of the U.S Space Program -- including the Apollo return capsule and the Galileo Probe.

In the last year, several aerocapture TPS candidate materials, both ablative and non-ablative, have undergone extensive arc jet testing. Advanced, lightweight structures have also been developed and are currently undergoing testing. Both heat flux and recession sensors are also being developed; some have been integrated into TPS and arc jet-tested. A 2-meter diameter carbon-carbon monocoque aeroshell was designed and manufactured by Lockheed Martin, and plans for non-destructive load testing for this aeroshell are scheduled to begin mid-2006. Future plans also include the manufacturing of a 1-m advanced, ablative aeroshell by Applied Research Associates that will be thermally tested at the Sandia National Laboratories in August. The above technologies are applicable to rigid body aerocapture concepts. Development of inflatable aerocapture technologies under ISPT began as concept definition studies. Although the inflatable concepts show promise of further reducing the propulsive mass, advancements of these concepts are not progressing at the same cadence as the rigid concepts due to funding limitations and their lower technology readiness.

Aerocapture is one of five candidate technologies for the New Millennium Program ST-9 mission. ST-9 would provide an opportunity to flight validate aerocapture computational modeling, design tools, and an integrated aerocapture system for future mission applications.

\section{Solar Electric Propulsion}

Solar Electric Propulsion (SEP) systems consist of several components: solar arrays, a power processing unit to convert power to the high voltages required by the engine, the propellant delivery system, the gimbal system to control the spacecraft, the thruster which includes a pair of negatively and positively charged grids, and the propellant. ISPT is maturing SEP systems by increasing their power, $I_{s p}$, and total throughput capability as well as investing in technologies to lower the cost of SEP systems. NASA Glenn Research Center (GRC), the lead for

2

\section{American Institute of Aeronautics and Astronautics}


NASA's Evolutionary Xenon Thruster (NEXT), is developing a Prototype Model (PM) 40-cm thruster, an Engineering Model (EM) Power Processing Unit (PPU), and an EM propellant feed system. These subsystem components will be integrated and tested in a single string system test. Planned efforts include long duration life and multi-thruster system testing. A new PPU for the state-of-the-art (SOA) NSTAR thruster that will share a common architecture with the NEXT is also being investigated for possible investment.

\section{A. Solar Electric Propulsion Technical Approach}

The electrostatic thrusters being developed rely on application of an electric field to accelerate the propellant directly. The propellant is initially ionized and then injected across a voltage potential established between an anode and cathode. The resulting force on the charged propellant ions accelerates them to high exhaust velocities. This type of device can achieve very high specific impulse (3,000 to 12,000 seconds and above) and is ideal for missions in which propellant mass must be minimized. These devices are generally limited to very low thrusts, but can achieve extremely high vehicle velocities due to their efficient propellant utilization. Ion propulsion and Hall thrusters fall in this category. The emphasis of the In-Space Propulsion Technology Program is on ion thrusters, though advancement of Hall Thruster technology is also part of the technology portfolio.

\section{B. Solar Electric Propulsion Status}

Ion engines have been demonstrated in space and are the primary propulsion system for NASA's DAWN mission. The first use of an ion propulsion system for primary propulsion was on the Deep Space 1 (DS-1) mission in 1998. The Discovery Program mission, DAWN, is scheduled to launch in 2007 and will be propelled to both Ceres and Vesta using NSTAR ion thrusters.

The ion engine on DS-1, NSTAR, jointly developed by NASA's GRC, Boeing, and NASA's Jet Propulsion Laboratory was designed to operate for one year at its maximum power level of $2.5 \mathrm{~kW}$. Over this time, the NSTAR thruster used approximately $83 \mathrm{~kg}$ of xenon propellant. Several long duration tests were performed to make sure the ion engine for DS-1 would last long enough to perform the mission. Beginning in the fall of 1998, the DS-1 flight spare engine was placed in a long duration test at JPL with the objective of demonstrating that the engine could be run for $150 \%$ of its design life. At the end of the JPL extended life test (ELT) in June, 2003, the NSTAR flight spare engine had operated for more than 30,352 hours and processed more than $235.1 \mathrm{~kg}$ of xenon. This is by far the longest any rocket engine has ever been operated and corresponds to $283 \%$ of its original design life. ${ }^{7}$

The In-Space Propulsion Technology Program is currently advancing SEP technology with the development of NEXT, which will demonstrate system level performance at power levels in excess of $7.0 \mathrm{~kW}$. As part of the design process, the NSTAR thruster ELT data and hardware were evaluated and that information used to significantly contribute to improving the NEXT thruster design. GRC also operated the NEXT 40-cm thruster for more than 2000 hours and identified additional design improvements for the prototype thruster now being incorporated into its design.

Hall thruster technology development includes both the SOA and advanced state-of-the art (ASOA) High Voltage Hall Accelerator (HiVHAC) thrusters, and both are scheduled to complete fabrication and undergo performance testing in the summer of 2006. The ASOA thruster will begin long duration wear testing in the fall of 2006. The anticipated lifetime of the ASOA thruster is greater than $30,000 \mathrm{hrs}$; several factors greater than existing technology. A decision will be made following the wear tests to determine if the ASOA thrusters warrants a full system development.

\section{Solar Sail Propulsion}

Solar Sails are large, lightweight structures that achieve thrust by reflecting solar photons. Two different 20meter Solar Sail Systems were developed and successfully completed deployment and functional vacuum testing last year in NASA Glenn's Space Power Facility at Plum Brook Station, Sandusky, Ohio. The sails were designed and developed by ATK Space Systems and L'Garde, respectively. The sail systems consist of a central structure with four deployable booms that support the sails. These sail designs are robust enough for deployments in a one atmosphere, one gravity environment and are scalable to much larger solar sails - perhaps as much as $150-\mathrm{m}$ on each side.

First generation sails will vary in size from $100 \mathrm{~m}-200 \mathrm{~m}$, depending on mission destination, and typically would be 3-axis stabilized. It would be compacted and stowed for launch. Once deployed, the sails would be supported by ultra-lightweight trusses. Solar sails are composed of flat, smooth material covered with a reflective coating and supported by the ultra-lightweight structures which are attached to a central hub. Near-term sails likely will use aluminized Mylar or CP-1. Both are materials previously flown in space and are currently under test for long term 
exposure to relevant environments for potential Solar Sail Missions. More robust sails might use a meshwork of interlocking carbon fibers. ${ }^{8}$

\section{A. Solar Sail Propulsion Technical Approach}

There are four classes of solar sails, defined by their operating environments. A solar sail could fly in low earth orbit, but it would need to be robust enough to withstand gravity and environmental loads greater than the other classes. Missions to the outer solar system and beyond require further innovations in architectures and materials to achieve those orbits within a reasonable trip time. While an interstellar probe is a notable, potential future mission application for sails, it is a far term vision. The most near term applications are for heliocentric missions in the Earth's neighborhood (the earth-sun L1 libration point for example). This class is the current focus of NASA's investments. It will lead to the next generation solar sail which will enable a close approach to the sun $(<0.25 \mathrm{AU})$ where thermal and radiation environment will be more stressing.

NASA is concentrating its development effort on the three-axis stabilized, square sails. This sail looks much like a kite. Four booms extend from a central hub that houses the four triangular sail quadrants during launch.

\section{B. Solar Sail Propulsion Status}

Two teams were selected by NASA to lead hardware development activities that culminated in ground demonstrations of key solar sail technology systems. L'Garde Inc., of Tustin, Calif., developed a solar sail system that employs inflatable booms that are flexible at ambient temperatures but "rigidize" at low temperatures. Their concept uses articulated vanes located at the corners of the square to control the solar sail attitude and thrust direction. Able Engineering Company, of Goleta, Calif., developed a coilable longeron boom system that deploys in space much the way a screw is rotated to remove it from an object. ${ }^{9}$ Attitude control is achieved with sliding ballast masses to offset the center of mass from the center of pressure of the sail. Roll control is achieved using spreader bars at the tips of the mast which causes the sail to behave much like a pinwheel.

Both hardware vendors fabricated and tested 10-meter subscale solar sails in the spring of 2004. In 2005 they conducted 20-meter subscale solar sail deployments at the Plum Brook facility. Solar sails are one of the candidate technologies for the New Millennium Program ST-9 mission.

\section{Advanced Chemical Propulsion}

SOA chemical propulsion systems are performing at or near their theoretical performance limits and provide the primary means of transportation for space payloads. The In-Space Propulsion Technology Program is working to incrementally improve the performance of these systems in two key areas: lightweight components and advanced propellants. In the area of lightweight components, the object is to decrease the mass of propellant and pressurant tanks and to reduce the dependence on Multiple Layer Insulation (MLI) by advancing a potential alternative for thermal and micrometeoroid protection. In the advanced propellant area, ISPT is working to increase the $\mathrm{I}_{\mathrm{sp}}$ of SOA earth storable bipropellant systems and determine their overall application to deep space exploration mission.

\section{A. Advanced Chemical Propulsion Development Approach}

NASA is investing in near-term, incremental improvements to SOA hardware and processes for in-space chemical propulsion systems. Lightweight components development includes optimizing, designing and testing cross-cutting propulsion components and subsystem technologies to reduce the overall system mass. The advanced propellant work focuses on evaluating high energy storable propellants with enhanced performance for in-space application as well as the development of supporting technologies that enable long-term storage of soft cryogens in low-g environments.

\section{B. Advanced Chemical Propulsion Technology Status}

Various propulsion/mission analyses and trades were conducted for missions to prioritize candidate propulsion technologies. The resulting strategy begins with improvements to today's pressure-fed systems leading to steady progress into future high performance systems that operate at higher pressures and temperatures. The current lightweight tank task is focused on reducing the mass of the propellant tanks, since tanks get heavier at higher pressures due to thicker walls. Improvements in bipropellant system performance can be harnessed without compromising risk. Greater performance can also be obtained from high temperature engines. However, high temperature thrusters lead the way to higher wall temperatures which must be addressed through improvements in thermal design and advances in materials and manufacturing processes. Temperatures of chemical thrusters have been limited by the traditional thruster chamber material, Columbium (Niobium), thereby constraining the 
propulsion system's performance. Incorporating high temperature, oxidation resistant combustion chamber materials, such as Iridium/Rhenium ( $\mathrm{IrRe}$ ) into innovative designs allows for higher chamber temperatures, leading to higher performance engines. These advancements in thrust chamber materials along with advanced pressurization and active mixture ratio control lead to an increase in $I_{s p}$. Combined with the development of more accurate flowrate and propellant gauging instrumentation, a significant reduction in the amount of on-board propellant may be realized. Future plans include the advancement of higher pressure combustion chambers (pressure-fed and pumpfed) and space storable propellants, both of which will increase the $I_{s p}$. Additional development within the Advanced Chemical Propulsion Area of the project includes work in aluminum loaded high $\mathrm{I}_{\mathrm{sp}}$ gelled propellants and Foam Core Shield micro-meteoroid protection systems.

\section{Conclusion}

In the first five years the In-Space Propulsion Technology Program has made significant advancements toward fielding the next generation of in-space propulsion technologies. With the manufacture of advanced electric propulsion engines, solar sail systems, and advanced aeroshells for aerocapture, ISPT will have built a framework for enabling or enhancing future robotic science and deep space exploration missions. The ISPT Project has reduced the risks involved with first use of these new technologies by operating-life tests on the SEP engines, ground deployments of subscale solar sails, as well as load and thermal testing performed on the subscale aeroshells. The set of project technology investment priorities that were established using an NASA-wide prioritization process in 2001 has changed little, allowing maturation of technologies requiring sustained investment.

\section{Acknowledgments}

The work described in this paper was funded by the In-Space Propulsion Technology Program, which is managed by NASA's Science Mission Directorate in Washington, D.C., and implemented by the In-Space Propulsion Technology Project at the George C. Marshall Space Flight Center in Huntsville, Alabama.

\section{References}

\footnotetext{
${ }^{1}$ Farris, B., Eberle, B., Woodcock, G., and Negast, B., "Integrated In-Space Transportation Plan," NASA/CR-2002212050,2002

${ }^{2}$ Hall, J., Noca, M., and Bailey, R., "Cost-Benefit Analysis of the Aerocapture Mission Set," AIAA-2003-4658, 39 AIAA/ASME/SAE/ASEE Joint Propulsion Conference, Huntsville, AL, July 20-23, 2003.

${ }^{3}$ Lockwood, M., "Titan Aerocapture Systems Analysis," AIAA2003-4799, 39 ${ }^{\text {th }}$ ALAA/ASME/SAE/ASEE Joint Propulsion Conference, Huntsville, AL, July 20-23, 2003.

${ }^{4}$ Miller, K., Gulick, D., Lewis, J., Trochman, B.,"Training Ballute Aerocapture: Concept and Feasibility Assessment," AIAA2003-4655, $39^{\text {th }}$ AIAA/ASME/SAE/ASEE Joint Propulsion Conference, Huntsville, AL, July 2023, 2003.

${ }^{5}$ James, B., Munk, M., Moon, S., “Aerocapture Technology Project Overview," ALAA2003-4654, $39^{\text {th }}$ AIAA/ASME/SAE/ASEE Joint Propulsion Conference, Huntsville, AL, July 20-23, 2003.

${ }^{6}$ Rayman, M., Varghese, D., Lehman, D., Livesay, L., "Results from the Deep Space 1 Technology Validation Mission," IAA-99-IAA.11.2.01, 50 $0^{\text {th }}$ International Astronautical Congress, Amsterdam, the Netherlands, 4-8 October, 1999.

${ }^{7}$ Sengupta, A., "NSTAR Extended Life Test Critical Findings," Jet Propulsion Laboratory Interoffice Memorandum, April 19, 2004.

${ }^{8}$ Montgomery, E., and Johnson, L., "Development of Solar Sail Propulsion for Inner Solar System NASA Science Missions," AIAA2004-1506, 45 th AIAA/ASME/ASCE/AHS/ASC Structures, Structural Dynamics and Materials Conference, Palm Springs, California, Apr. 19-22, 2004

${ }^{9}$ Lichodziejewski, B., West, J., Reinhart, R., Belvin, K., and Pappa, R., "Brining an Effective Solar Sail Design Toward TRL 6," AIAA2003-4659, $39^{\text {th }}$ AIAA/ASME/SAE/ASEE Joint Propulsion Conference, Huntsville, AL, July 20-23, 2003.
} 


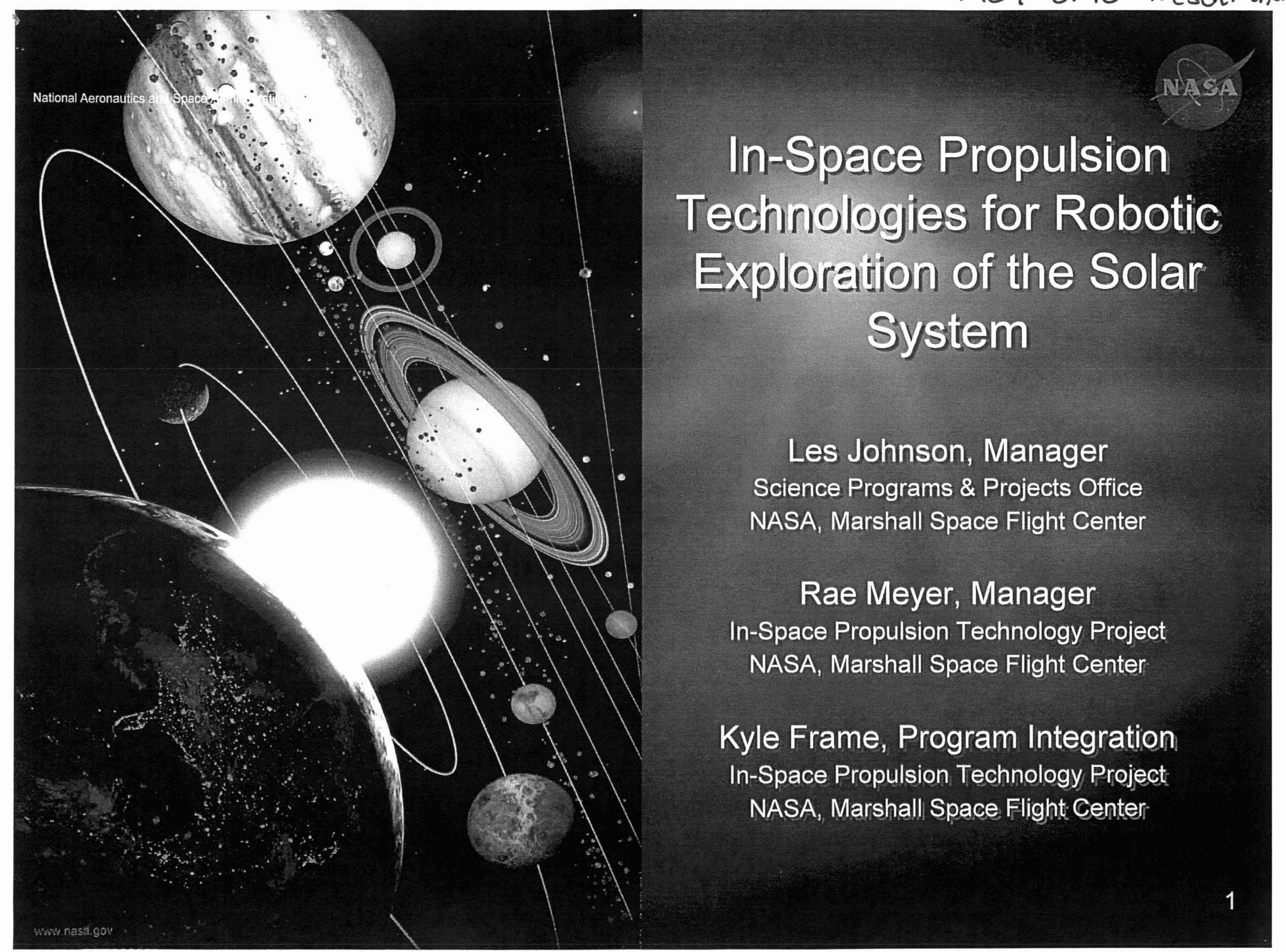



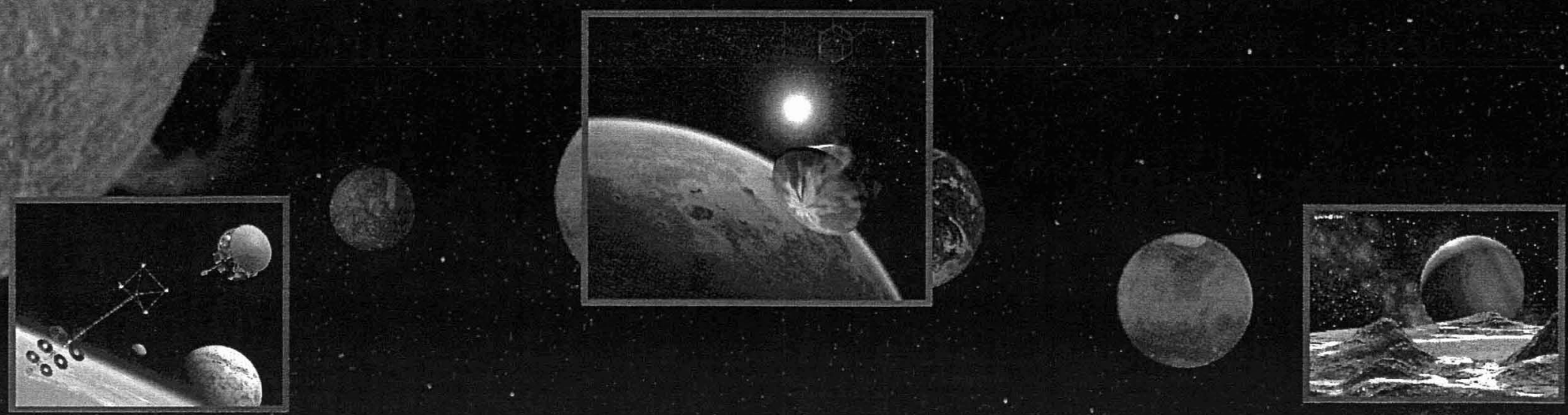

\section{In-Space Propulsion Technology Project (ISP) Objective:}

To develop in-space propulsion technologies that can enable and/or benefit near and mid-term NASA science missions by significantly reducing cost, mass, and/or travel times.
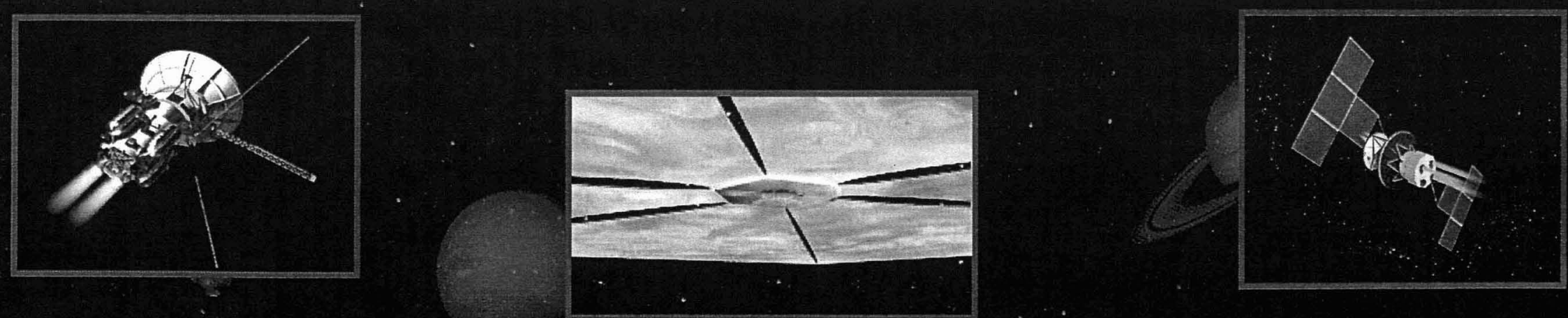

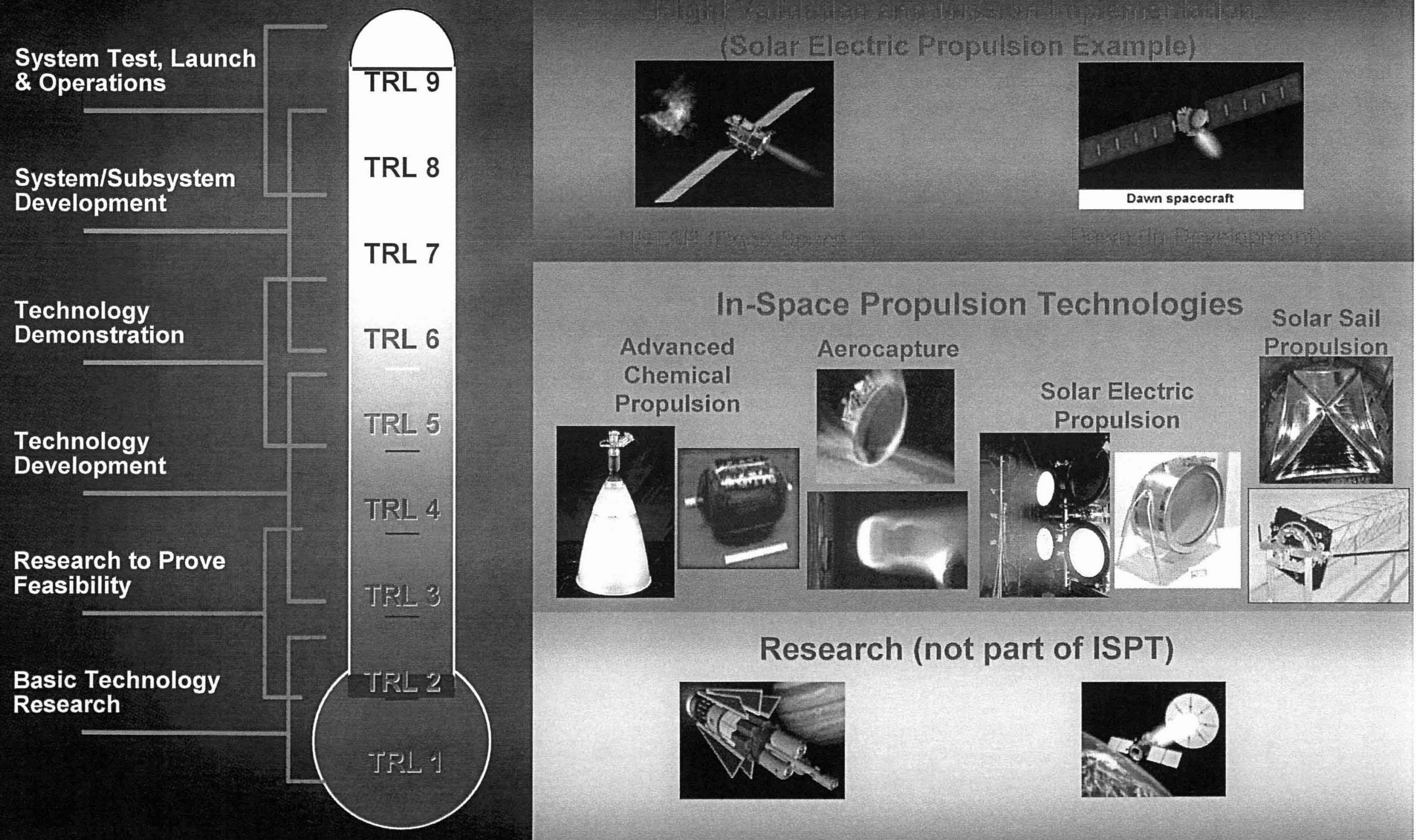

Research (not part of ISPT) 


\section{Initial IISTP Results \& FY01/02 ISP Priorities}

\section{CONSENSUS SCORING}

\begin{tabular}{|c|c|c|c|c|}
\hline HIGH & MEDIUM & LOW & $\begin{array}{c}\text { HIGH PAYOFFI } \\
\text { HIGH RISK }\end{array}$ & DROP \\
\hline $\begin{array}{c}\text { Aerocapture } \\
\text { (for robotic \& HEDS) }\end{array}$ & Solar Sails & Solar Thermal & Plasma Sail & NTP \\
\hline SEP Ion $(5 / 10 \mathrm{~kW})$ & SEP Hall $(100 \mathrm{~kW})$ & $\begin{array}{c}\text { Bi-modal NTP } \\
\text { (Low- to High-Power } \\
\text { Scalable) } \\
\end{array}$ & MXER Tether & \\
\hline \multirow[t]{3}{*}{$\begin{array}{c}\text { NEP (Low- to High-Power } \\
\text { Scalable) }\end{array}$} & $\begin{array}{c}\text { Class I Electric Propulsion } \\
(30 \mathrm{~kW}-100 \mathrm{~kW} \\
3,000-10,000 \mathrm{sec} \\
\text { eff }>50 \%)\end{array}$ & & Solar Sail $(1 \mathrm{gm} / \mathrm{m} 2)$ & \\
\hline & $\begin{array}{c}\text { Advanced Chemical (cryo } \\
+ \text { TBD) }\end{array}$ & & & \\
\hline & $\begin{array}{l}\text { Class II Electric Propulsion } \\
\qquad \begin{array}{c}>500 \mathrm{~kW} \\
>3000 \mathrm{sec} \\
\text { eff }>50 \%)\end{array}\end{array}$ & & & \\
\hline
\end{tabular}

ISP was originally chartered to be the In Space Propulsion Technology Project for the Agency 


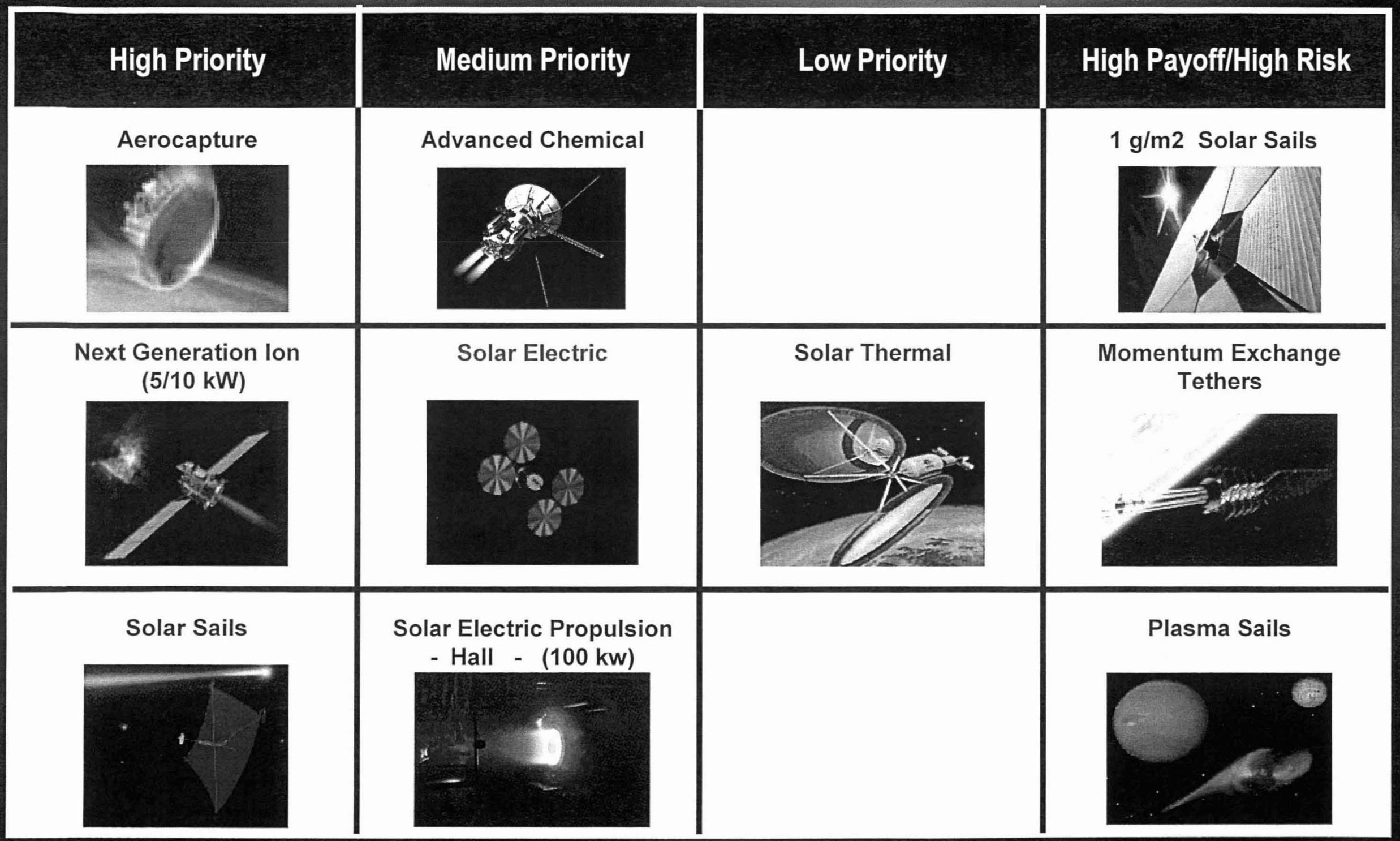


Current In-Space Propulsion Technology Priorities (SMD Focus)

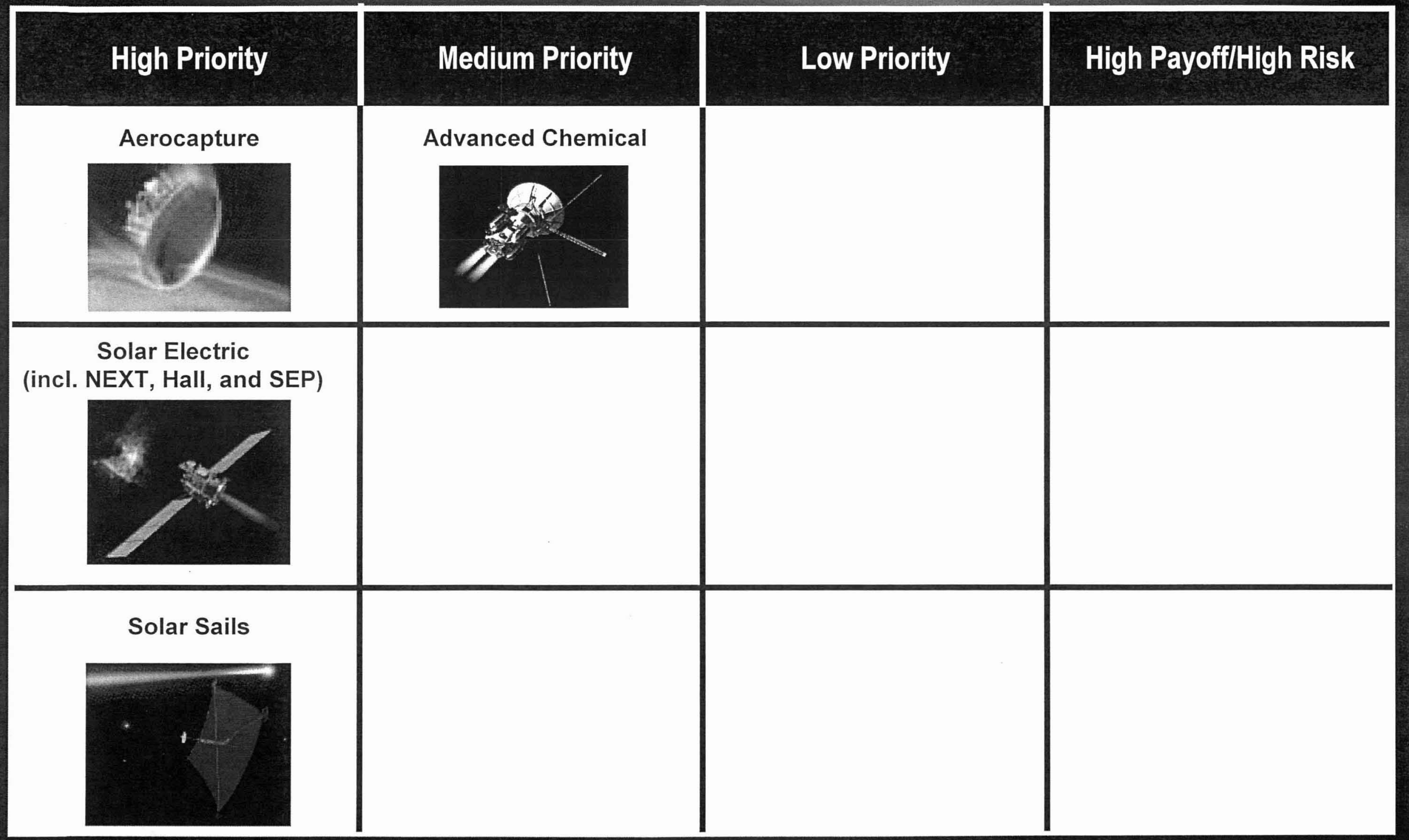


The Ant of Aeracapture

How atmospheric drag
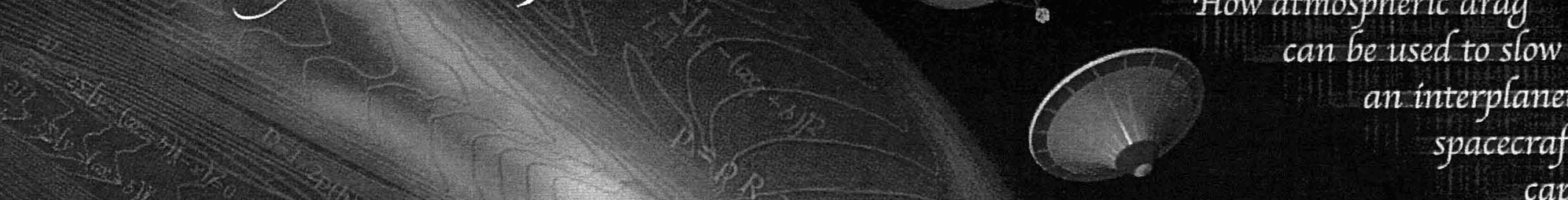

can be used to slow

an interplanetary

spacecraft and

capture it
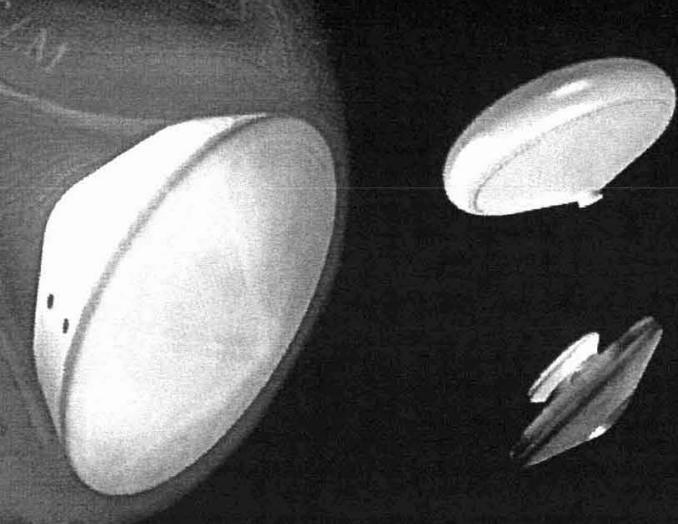

into orbit
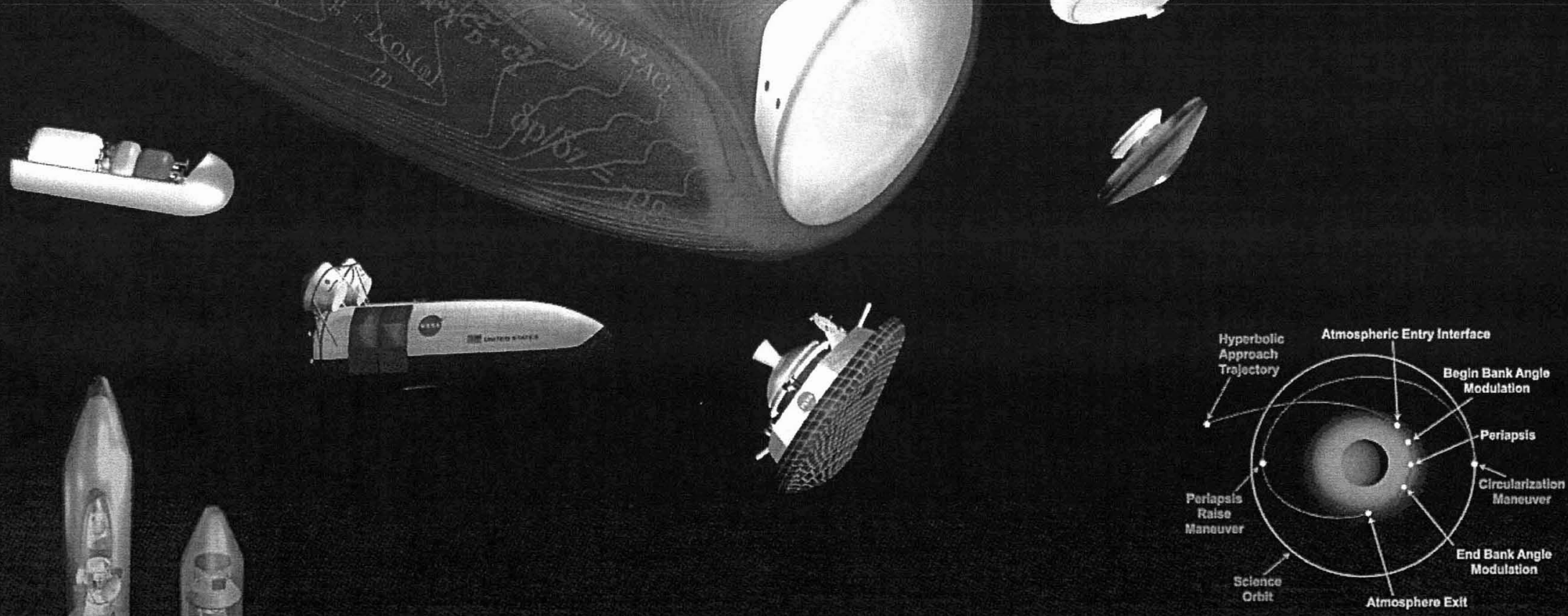

Cs: $x^{2}$
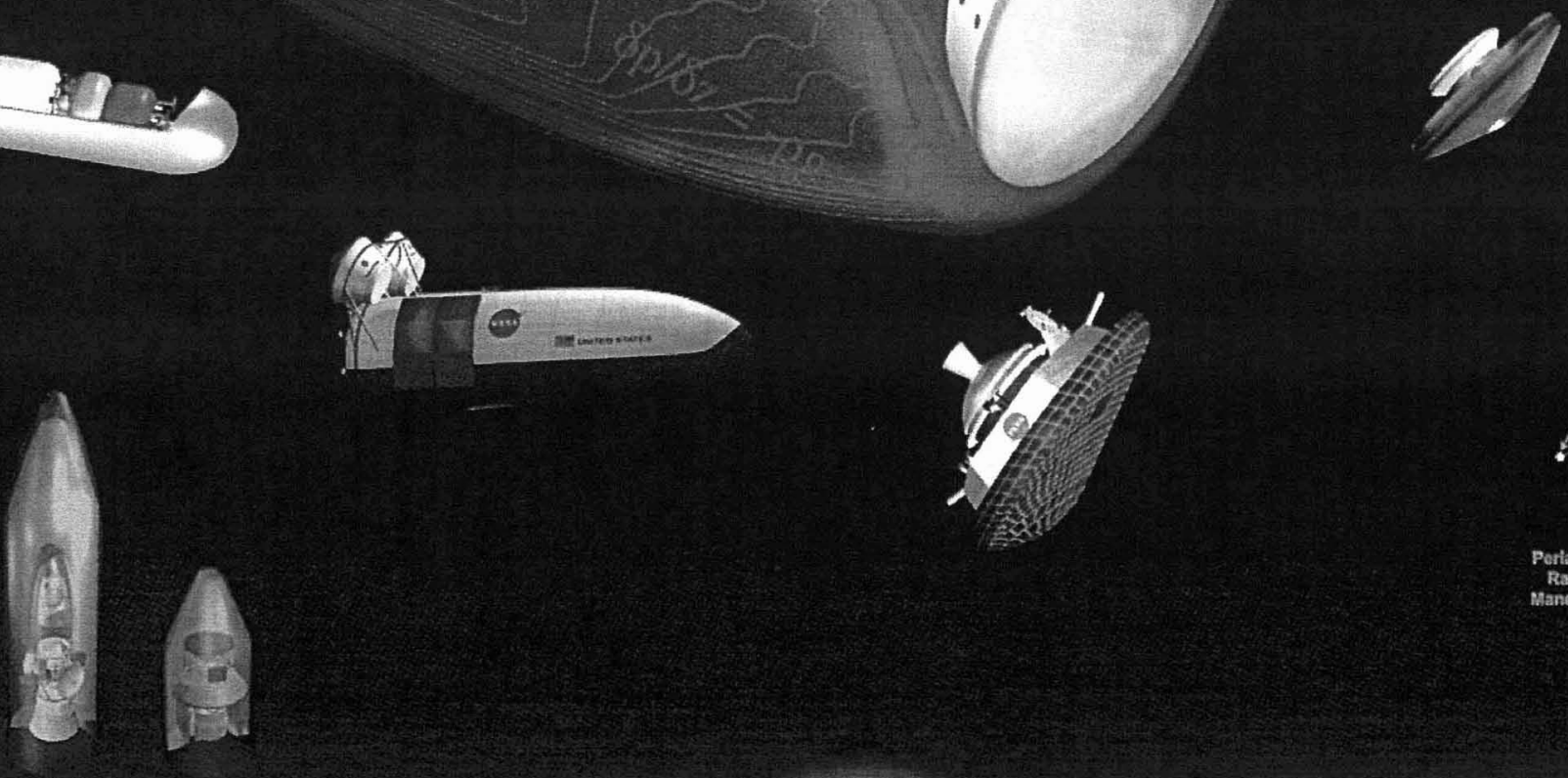

invelispacertropusisoncom 


\section{Basics of Aerocapture}

\section{Features}

- Spacecraft protection necessary

- Requires autonomous GN\&C

- Much higher useful payload fraction than for standard chemical propulsion or aerobraking orbit establishment

- Achieves required orbit faster than with aerobraking (hours vs. weeks/months)

- Key disciplines:

- Aerothermodynamics

- Atmospheric modeling

- Guidance, navigation and control

- Trajectory design

- Structures and materials

- Thermal protection systems

- Instrumentation

- Systems engineering and integration

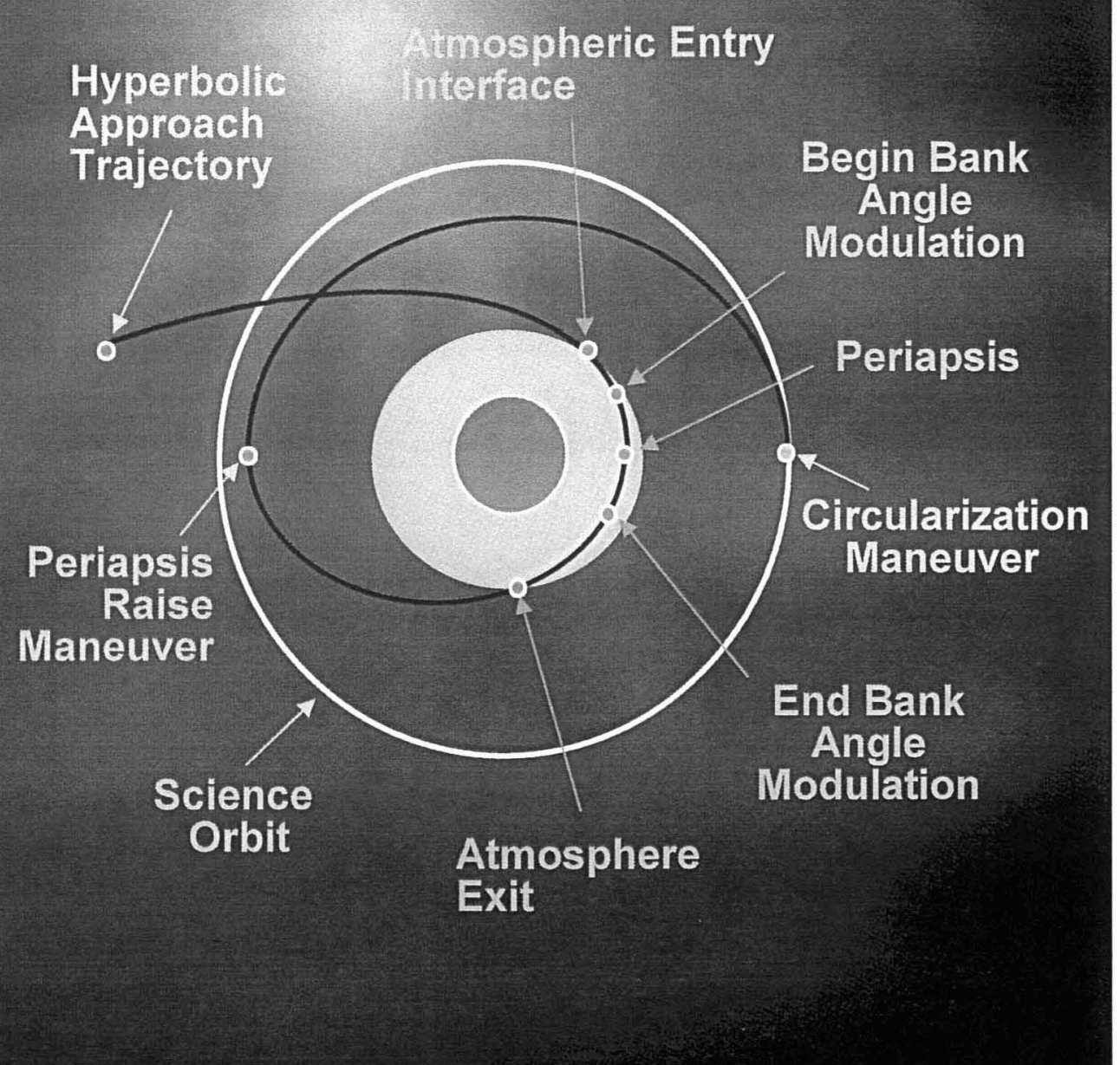




\section{Aerocapture Technology Alternatives}

\section{(Higher Maturity)}

Blunt Body Designs

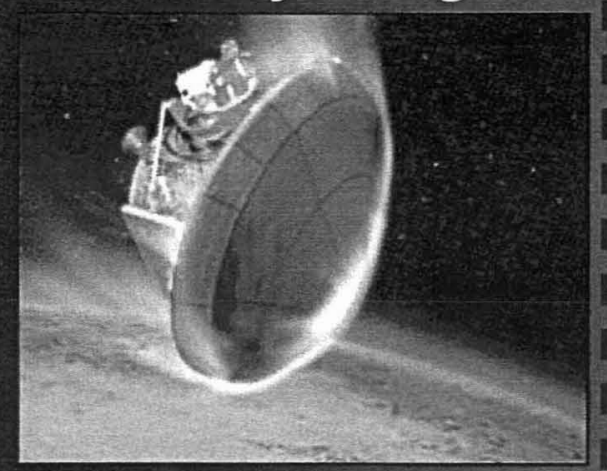

- Moderate to high maturity for small bodies; low to moderate maturity for other planets

- Provides modest tolerance for navigation and atmospheric uncertainties
Slender Body Designs

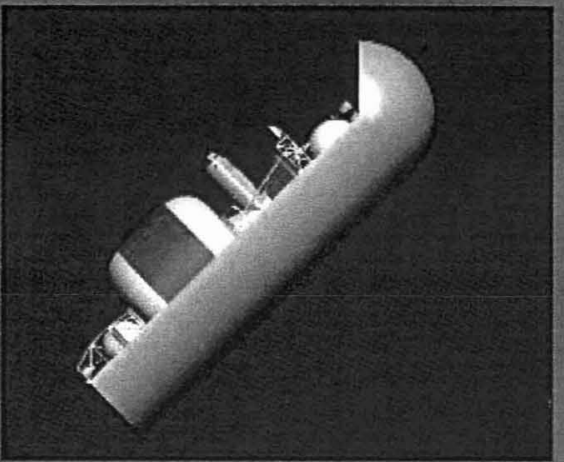

- Low to moderate maturity

- Provides increased tolerance for navigation and atmospheric uncertainties

- Provides increased volume and improved packaging advantages for larger spacecraft.

\section{(Lower Maturity)}

Trailing Ballutes

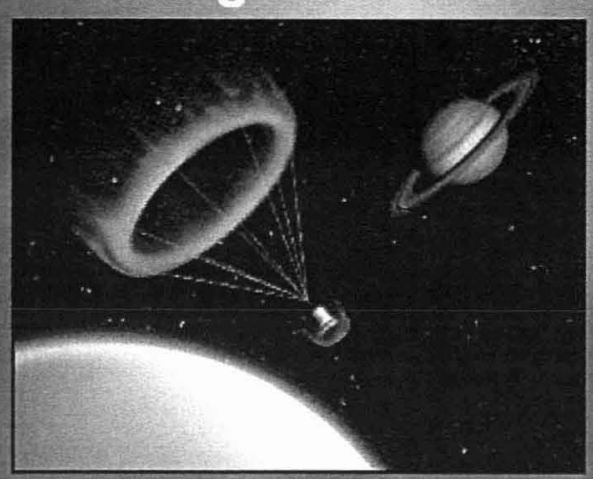

- Low maturity

- Applicable to all size and shape payloads

- May have performance advantages over Blunt Body, such as not having the payload enclosed during interplanetary cruise

\section{Attached Ballutes}

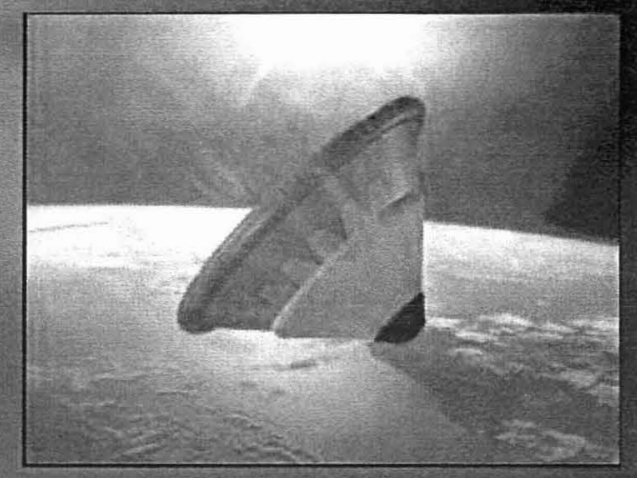

- Low to moderate maturity for Earth and Mars

- Developed and launched in 1996 by Soviet Union as part of Mars penetrator mission. Launch vehicle failure.

- Investigating feasibility of using aerodynamic lift for precision trajectory control

- Has potential volume and packaging advantage for larger spacecraft 


\section{Aerocapture Overview}
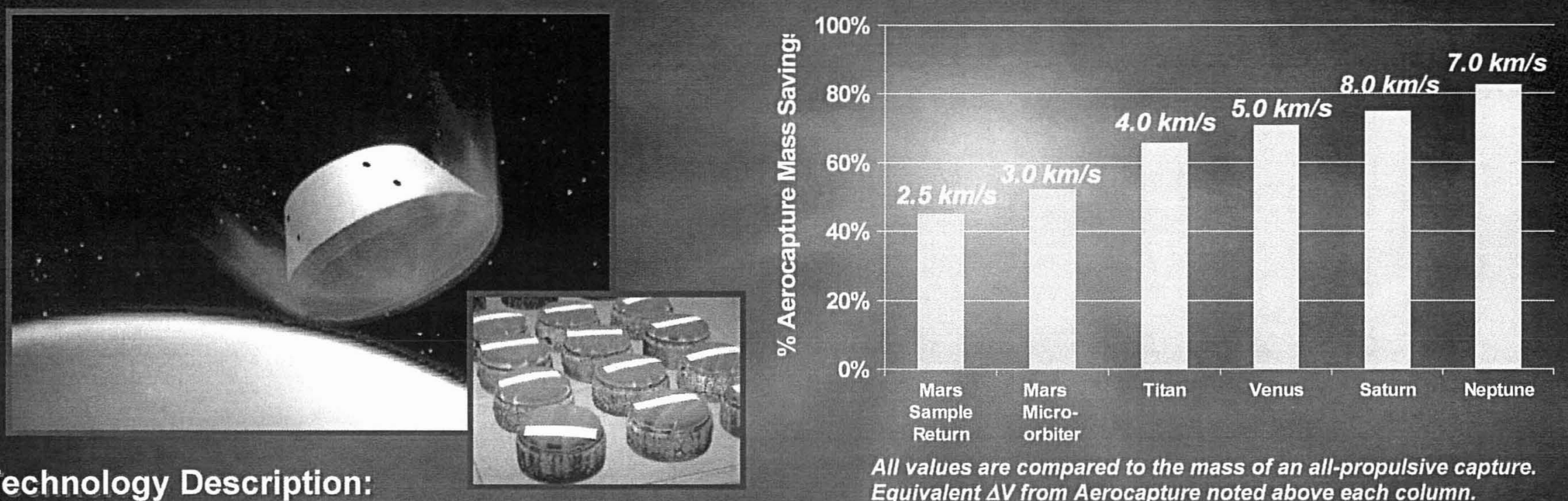

- Technology Description:

All values are compared to the mass of an all-propulsive capture. Equivalent $\Delta V$ from Aerocapture noted above each column.

- Aerocapture technology uses the atmospheres of planetary bodies to reduce the speed of a vehicle allowing for quick, near-propellantless orbit capture. The atmosphere is used as a brake, transferring the energy associated with the vehicle's high speed into thermal energy.

\section{- Benefits:}

- Capable of high delta $V$ at target arrival (multi-g deceleration).

- Significant reduction in trip times to outer planets (by allowing higher Earth departure or encounter energies).

- No or very little propellant required for orbit insertion/entry; saves mass which can save cost or enable greater scientific return.

- Autonomous aerodynamic control technology also enables precision landing.

- Technology Area Status

- Four awards developing advanced TPS concepts, structures and adhesives to enable a low-mass aeroshell with integrated TPS - hardware development and tests are underway

- Trade Studies, conceptual design, and hardware development and testing in the areas of advanced aerodynamic decelerators (trailing ballutes, attached ballutes and inflatable aeroshells)

- Heat flux and recession sensors in development for rigid aeroshells. Preliminary sensor design complete, fabrication and testing underway.

- In-depth systems definition studies of aerocapture at Titan and Neptune complete. Systems definition study of aerocapture at Venus completed in FYO4. Mars study underway, to be finished in FY06. 

Developed and Being Tested
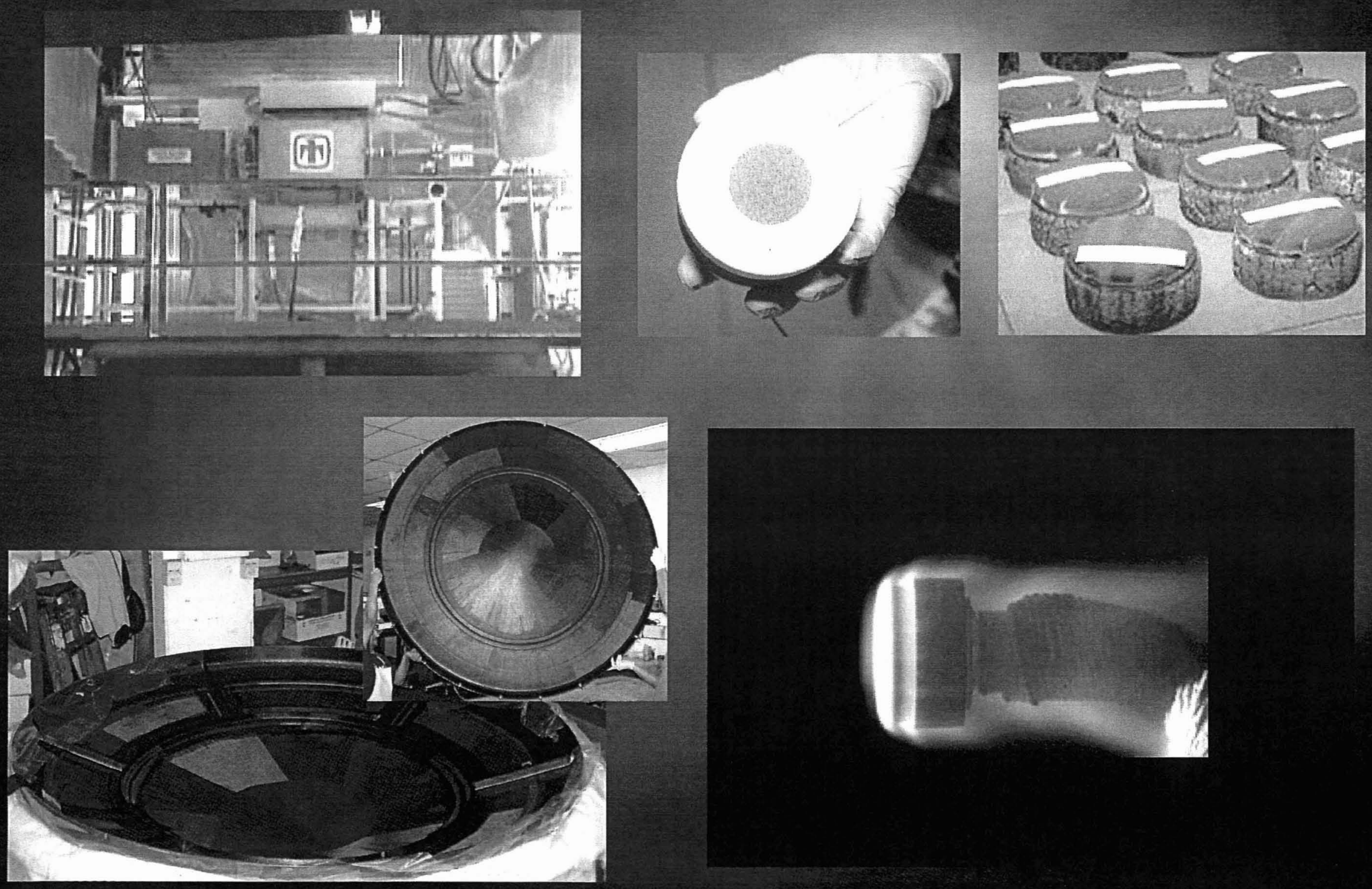


\section{Solar Electric Propulsion}

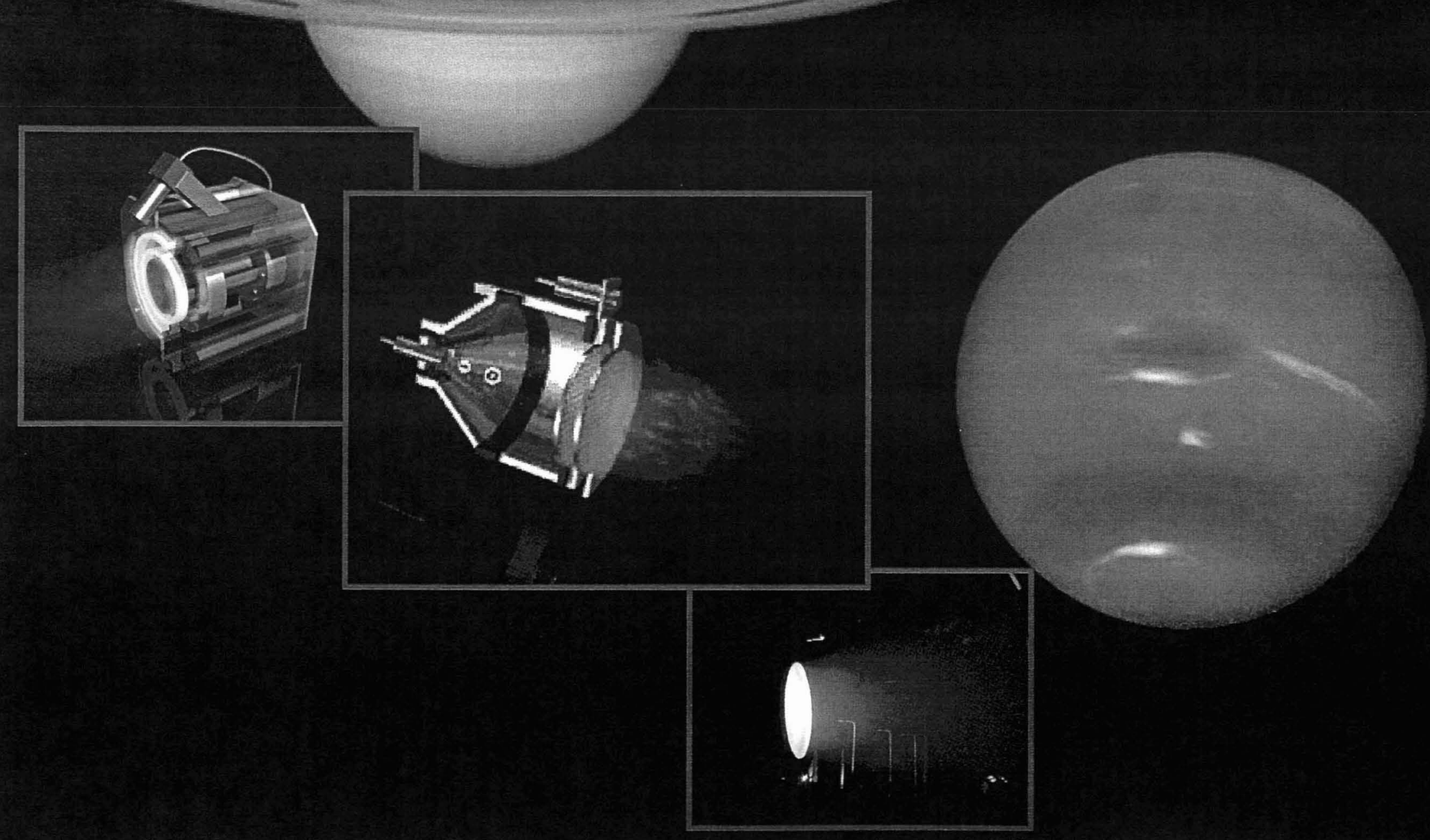




\section{Solar Electric Propulsion}

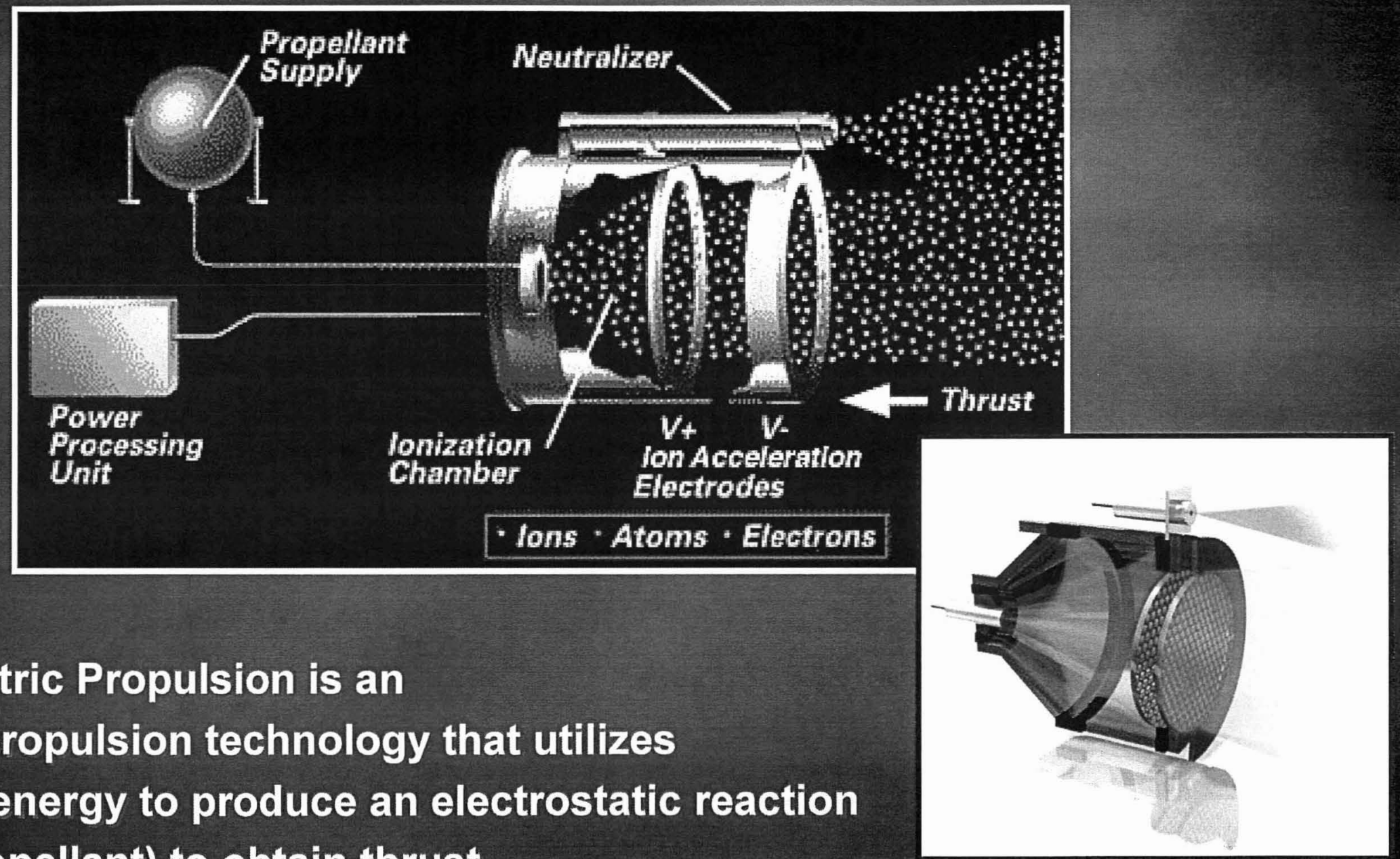

Solar Electric Propulsion is an in space propulsion technology that utilizes electrical energy to produce an electrostatic reaction (with a propellant) to obtain thrust. 


\section{Solar Electric Propulsion}

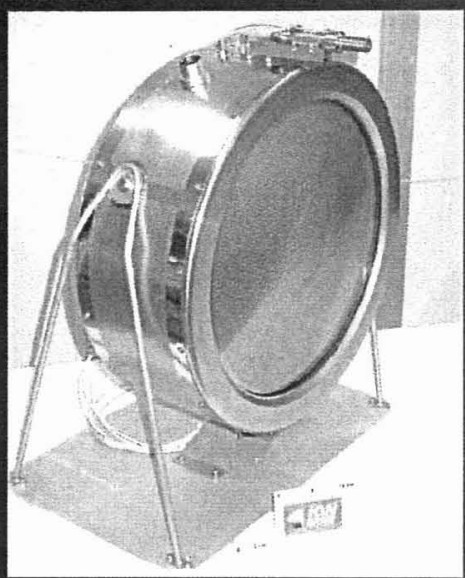

NEXT Thruster

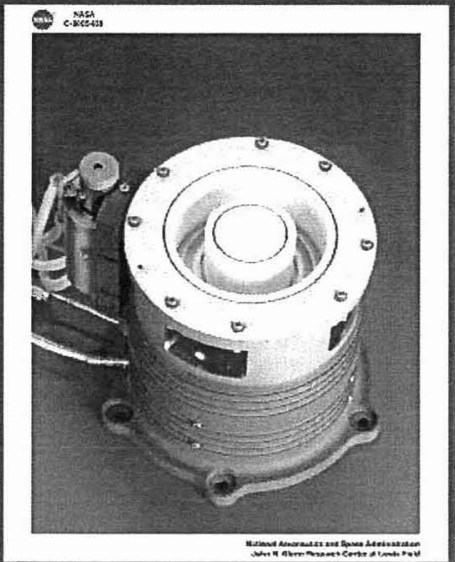

HIVHAC Thruster
- Technology Description

- Electric propulsion is most broadly defined as the acceleration of propellants by electrical heating, electric body forces, and/or magnetic body forces. Electric propulsion systems are capable of providing continual low thrust for long periods of time. For many destinations, the final velocities delivered by SEP engines are equal to or higher than those achieved with chemical propulsion.

- General Benefits Compared to SOA Chemical:

- Lower propellant consumption (ideal for high $\Delta \mathrm{V}$, high total impulse missions)

- Less propellant mass required, potentially lowering launch cests or increasing payload mass

- Reduced planetary trip times (continual acceleration versus impulse and coast)
- Gridded Ion Propulsion Technology Status:

- GRC is leading the development of NASA's Evolutionary Xenen Thruster (NEXIT), including a Proto-type Model (PM) 40-em thruster, an engineering model (EM) Power Processing Unit (FPU), arid an EMI propellant feed system. These subsysiem comperrienis will be integrated and tested in a single stririg sy stem test at JPL in FY07. On-going efforts will include lenge dirration life and multi-thruster system testing. Except for full life testing, NEXT is expected to reach TRL 6 in CY2006. Advanicements over state of the art (NSTAR) are provided below:

\begin{tabular}{|l|l|l|}
\hline \multicolumn{1}{|c|}{ Thruster Attribute } & NSTAR & \multicolumn{1}{c|}{ NEXT } \\
\hline Max. Input Power, kW & 2.3 & Up to 7 \\
\hline Throttle Range & $4: 1$ & Up to 12:1 \\
\hline Max. Specific Impulse, S & 3,170 & 4,190 \\
\hline Efficiency @ Full Power & $62 \%$ & $71 \%$ \\
\hline Propellant Throughput, kg & 235 & $>300$ (design) \\
\hline Specific Mass, kglkW & 3.6 & $\sim 2.5$ \\
\hline
\end{tabular}

- A standard architecture is being developed for IPS power and propellant management systems. The goal is to provide modular/flexible components to reduce costs, improve manufacturability, and enable a broad mission set

- Hall Thruster Technology Status:

- GRC/Aerojet are developing a high voltage, low power (0.3) $\mathrm{kW}-3.6 \mathrm{~kW}$ ) Hall effect thruster (HiVHAC) for the Science Mission Directorate (SMD). The low power Hall thruster is designed to provide a low cost SEP system for Discovery and New Frontiers cost-capped missions. Performance testing has been completed. Long-life thruster variants are currently undergoing fabrication, and extended duration testing will begin in FY06. 


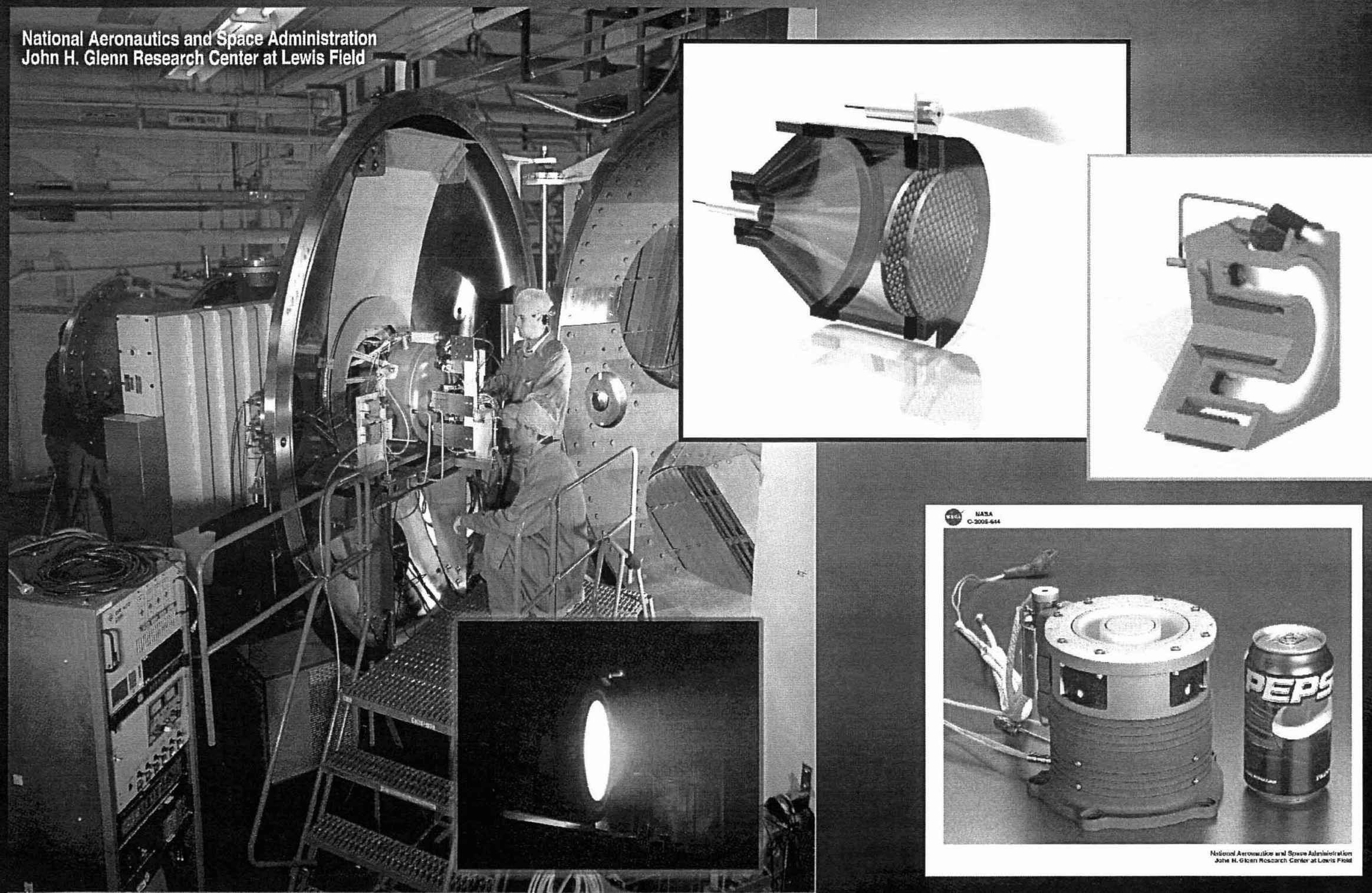




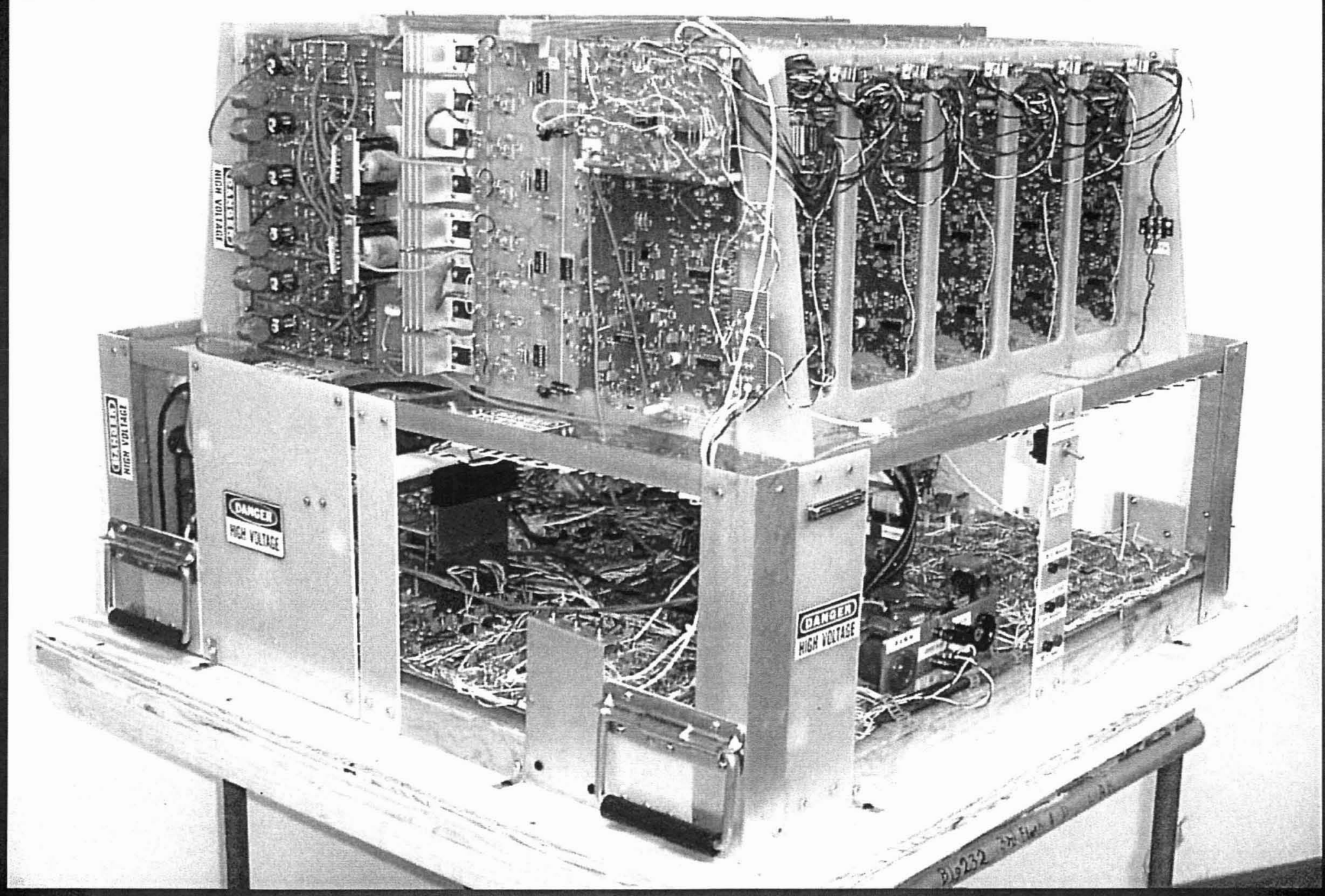

Solar Electric Propulsion System Power Processing Unit 


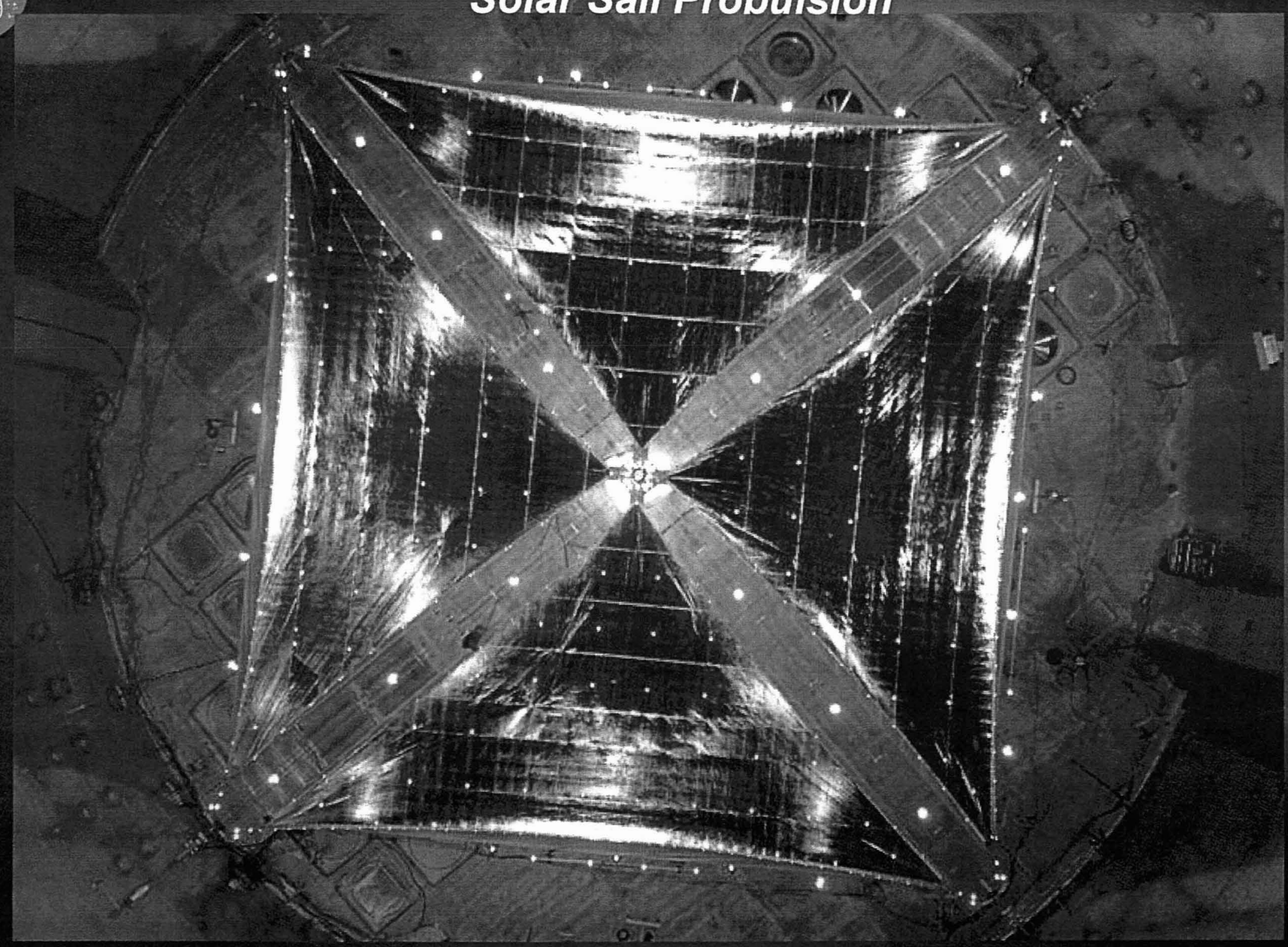




\section{Solar Sails}

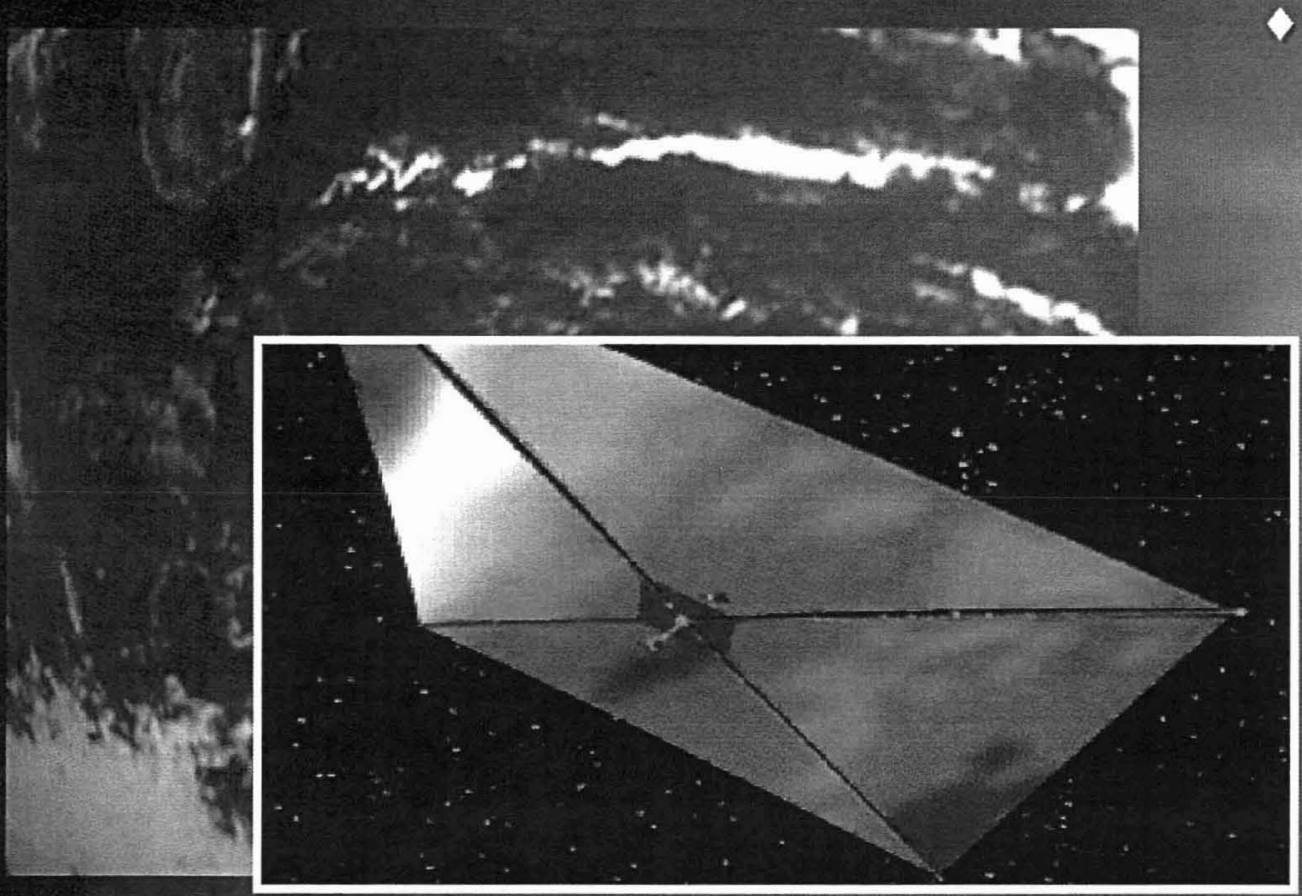

START SCIENGE OPERATIONS: 3-8-17

LAUNCH: 3-19-12

$\mathrm{C}_{3}=0.25 \mathrm{~km}^{2} / \mathrm{s}^{2}$

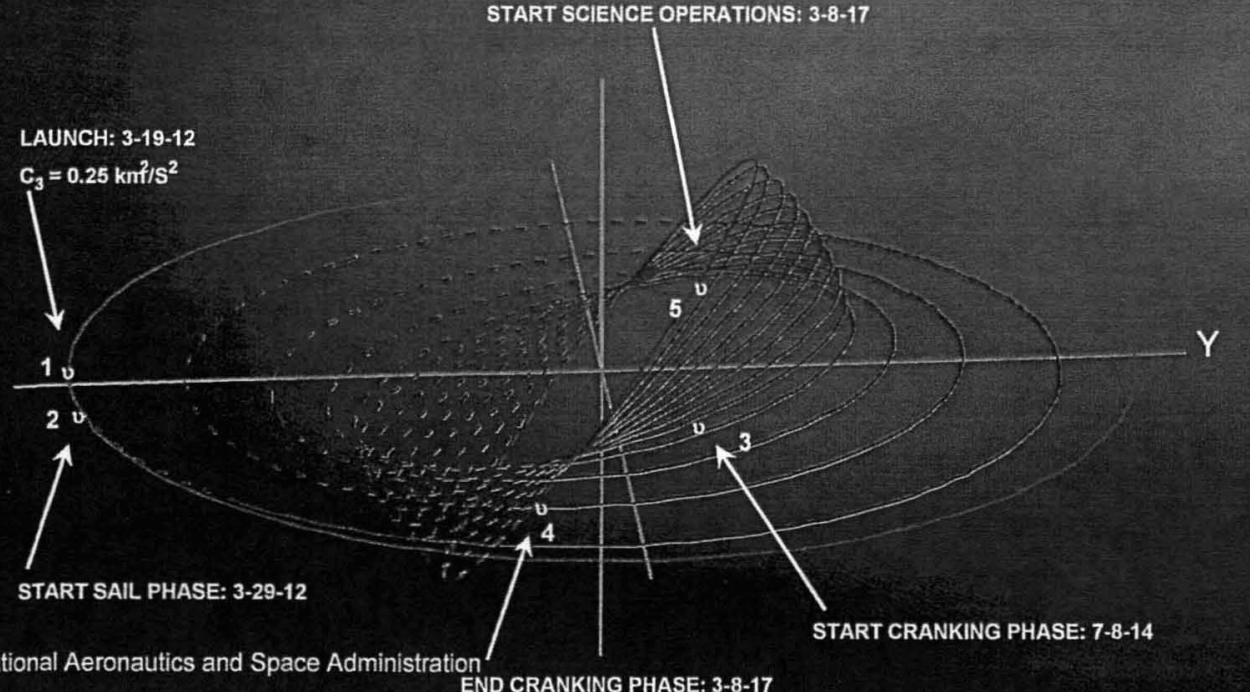

- Solar sails use photon "pressure" or force on thin, lightweight reflective sheet to produce thrust. Sails can operi ly riew regions of the solar systiens io accessibility for important science missions, with no propellants required.

$150 \mathrm{~m}$

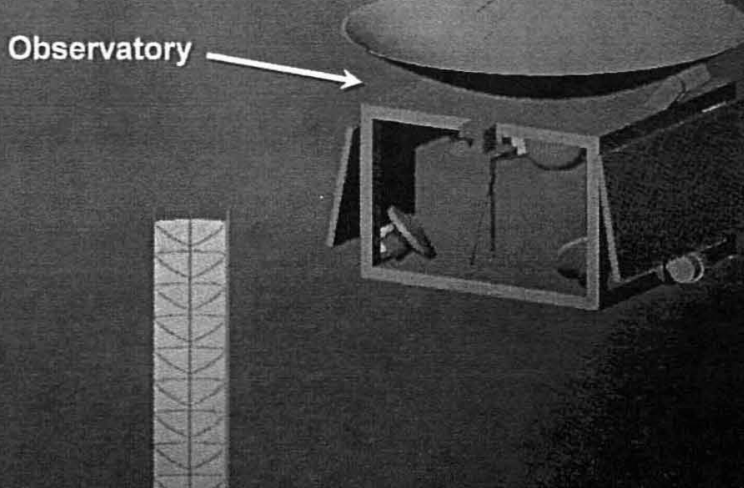

Sail Module 


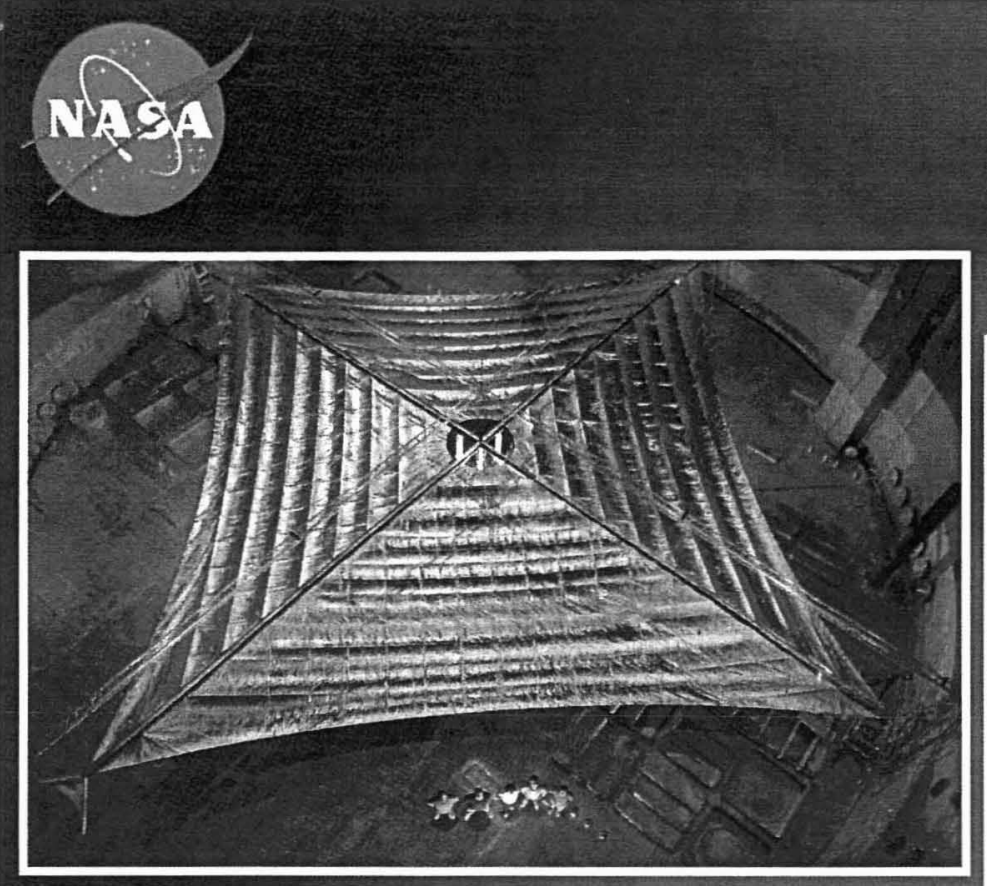

\section{Solar Sails}

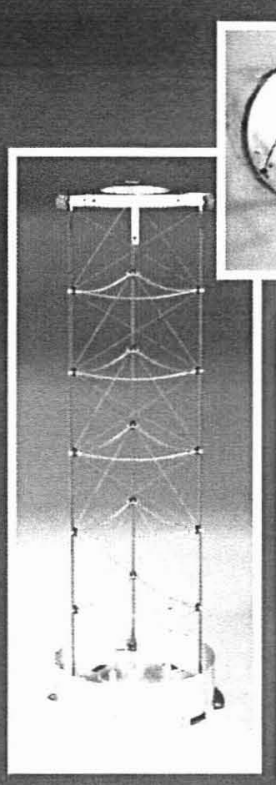

- General Description:

- Propellantless propulsion utilizes solar photon pressure ( $<9$ Newtons $/ \mathrm{km} 2$ ) to obtain thrust. Sail film is compactly stowed for launch and deployed / supported by ultra-light weight trusses.

- Technology Benefits:

- No propellants required

- Low system complexity (challenge is scaling to large area with ultra-low density)

- Low environmental impact on payload

- Enables access to previously inaccessible orbits (e. g., non-Keplerian, fixed reference, and high solar latitudes, etc.)

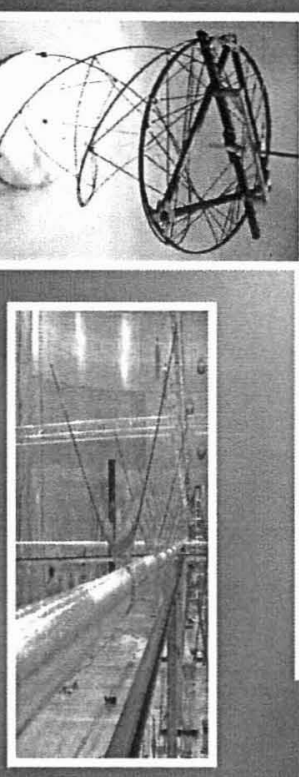

- Technology Area Status:

- Two parallel awards to design, fabricate, and test competing sail concepts for system level ground demonstration:

- $10 \mathrm{~m}$ system ground demonstrators were developed and tested in 2004.

- $20 \mathrm{~m}$ system ground demonstrators designed, fabricated, and tested under thermal vacuum conditions in 2005.

- Multiple awards to develop and test highfidelity computational models, tools, and diagnostics.

- Multiple awards for materials evaluation, optical properties, long-term environmental effects, charging issues, smart adaptive structures. 


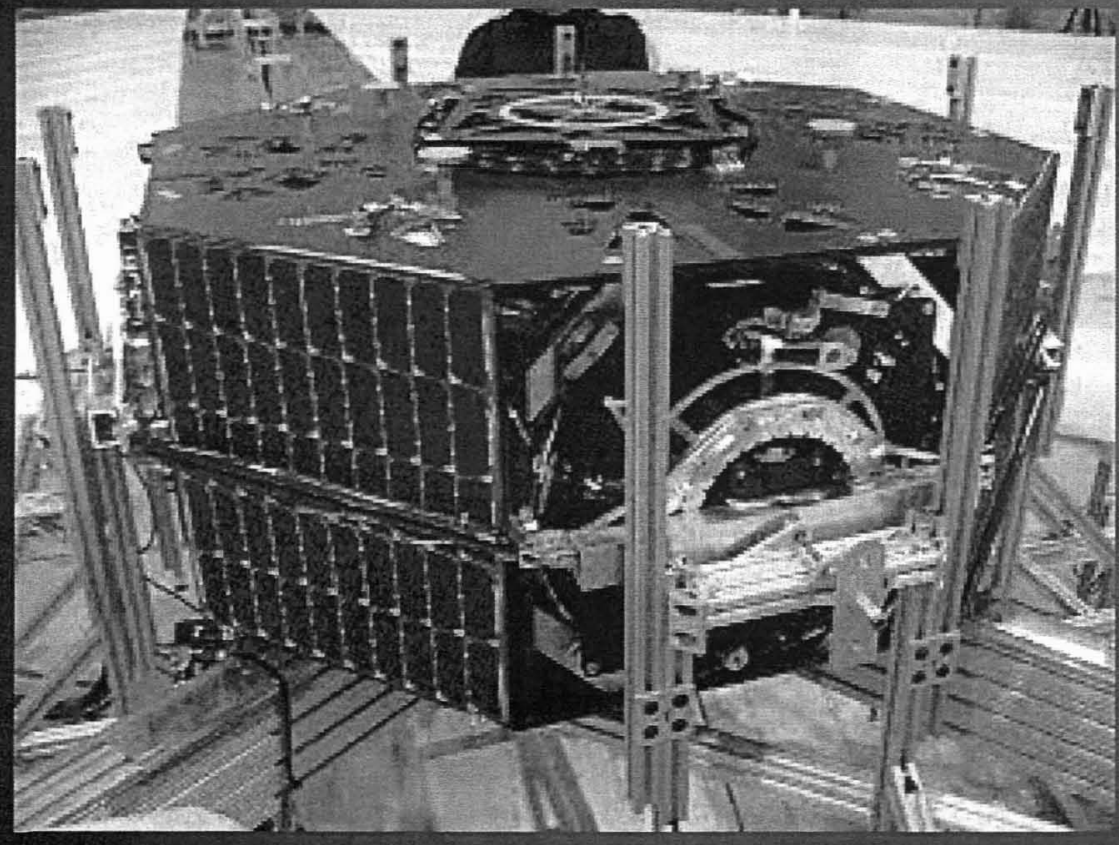

ATK $20 \mathrm{~m}$ Deployment

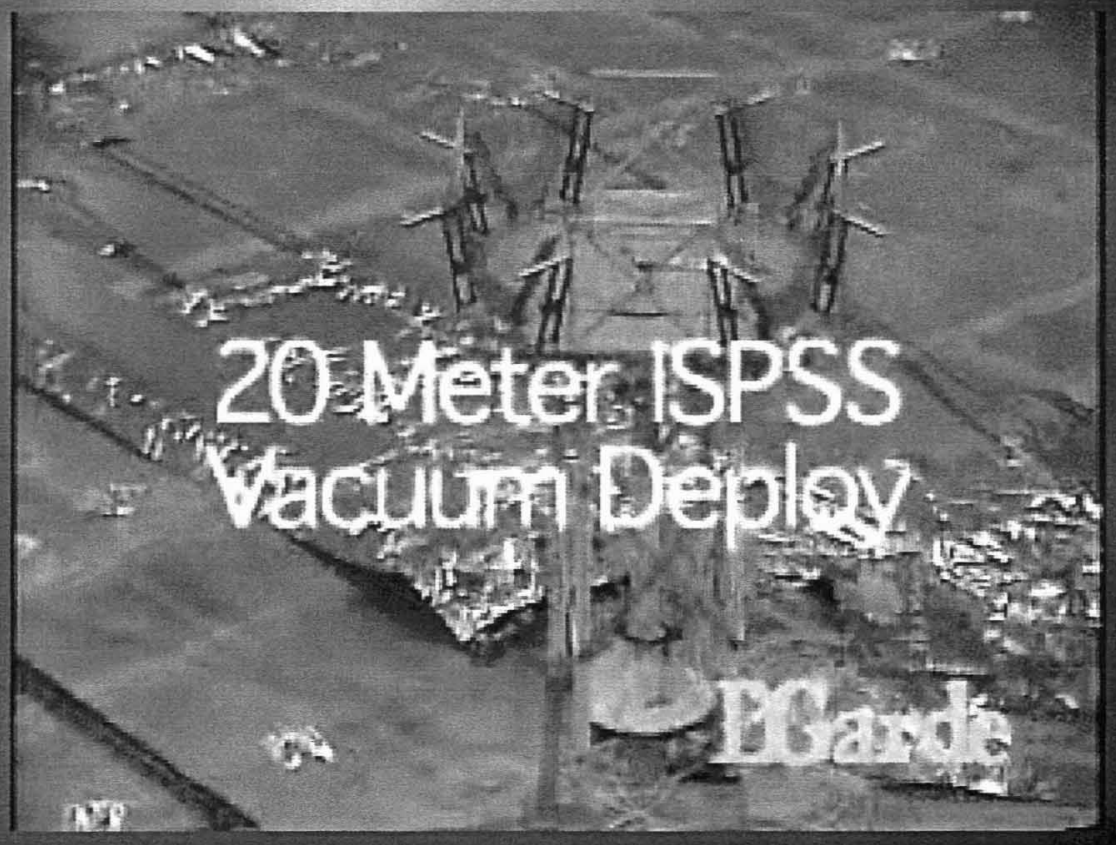

L'Garde 20 m Deployment 


\section{Advanced Chemical Propulsion (ACP)}

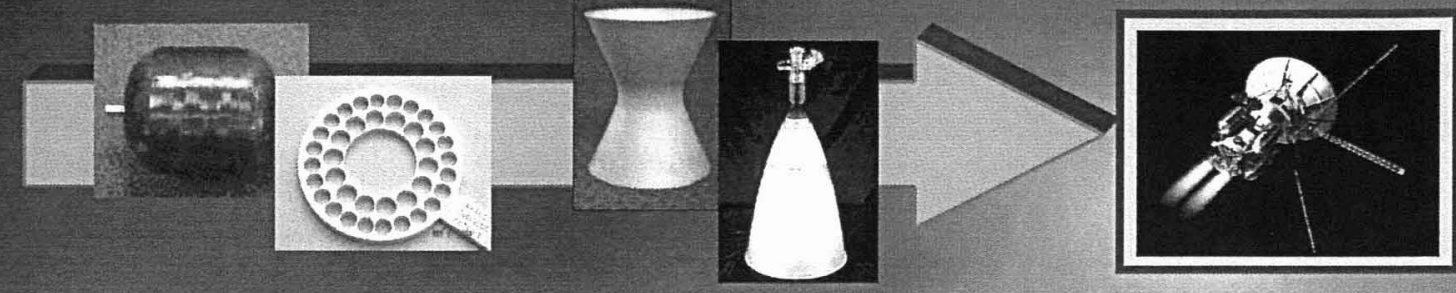

\section{Technology Objectives and Benefits \\ - Develop evolutionary improvements in chemical propulsion system performance that yield near- term products and directly impact payload mass fraction and cost. \\ - Resulting in greater science \\ - Producing higher performance than SOA chemical systems \\ - Increasing the reliability of propulsion systems}

\section{Focus areas}

- Lightweight / optimized components - component, subsystem, and manufacturing technologies that offer measurable system level benefits

- Advanced propellants - evaluation of high-energy storable propellants with enhanced performance for in-space application

\section{Advanced Propellants Tasks}

- Advanced lonic Monoprops

- Assessment of high performance monoprop potential through laboratory test and simulation

\section{Lightwejght components tasks}

- Ulfra-lighity/ejght Tank Technology (ULTT)

- Optimization of COPVs that will decrease the mass of propellant and pressurant tanks. Includes acceptance / margin testing to increase design allowables and reduce risk

- Cycle 3 High Temp Biprop Thruster

- Leverage high temperature thrust chamber material potential to optimize existing engine designs and demonstrate increased $I_{\mathrm{sp}}$ to $>335$ s

- High Temperature TCA Materials

- Investigation of materials and manufacturing processes, e.g., VPS, to provide high temperature options for thrust chamber assemblies (TCAs)

- Active Pressurization \& Mixture Ratio (M/R)

- Active M/R laboratory demonstration using non-hazardous fluids to simulate a small, deep space, pressure-fed propulsion system 


\section{Advanced Chemical Propulsion}
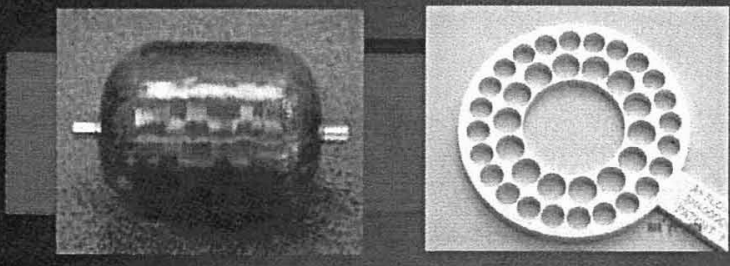

- Advanced Propellants: Storable chemical propulsion concepts that offer significantly increased performance and supporting technologies that may enable long-term storage of cryogens in low $g$

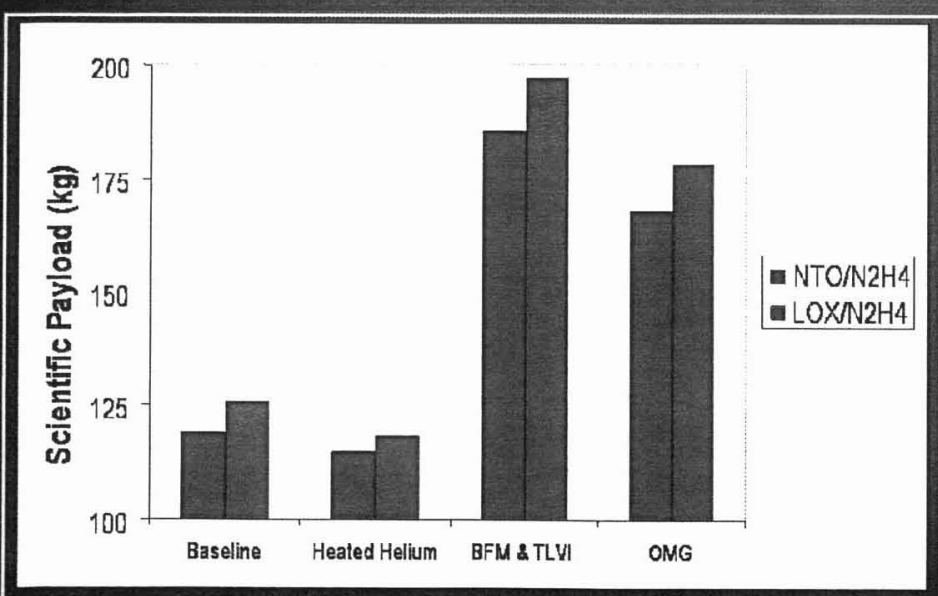

Active mixture ratlo control results in a $56 \%$ Increase In sclence payload Nationar AEerontautics and Space Auministratio

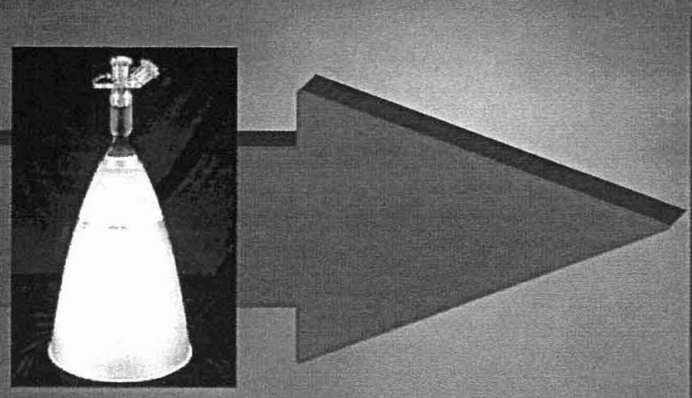

- Lightweight Components:

Optimized component, material and manufacturing technology to reduce the mass and increase the reliability of cross-cutting propulsion components: feed system components, tanks, etc.
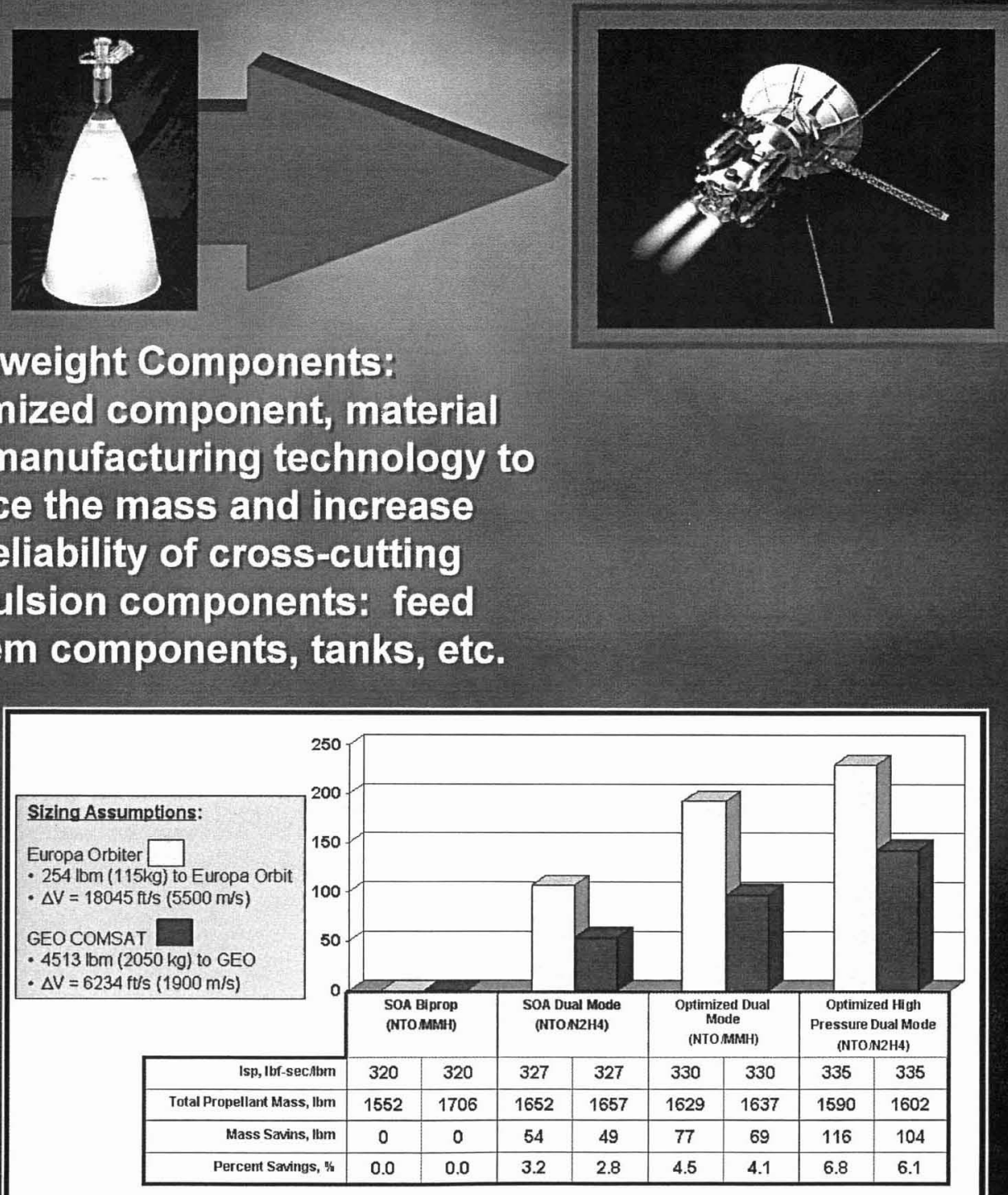


\section{New Millennium Program Flight Opportunity}

- ISP is pursuing partnerships to compete (under the New Millennium Program ST-9)) for the opportunity to flight demonstratie first generation products:

- Aerocapture (Rigid Aeroshell and TPS)

- 1 AU Solar Sail

- Proposed parthership will provide leveraging of ISP technology developments, funding and management experience to strengthen proposal development and potential resulting flight demonstration
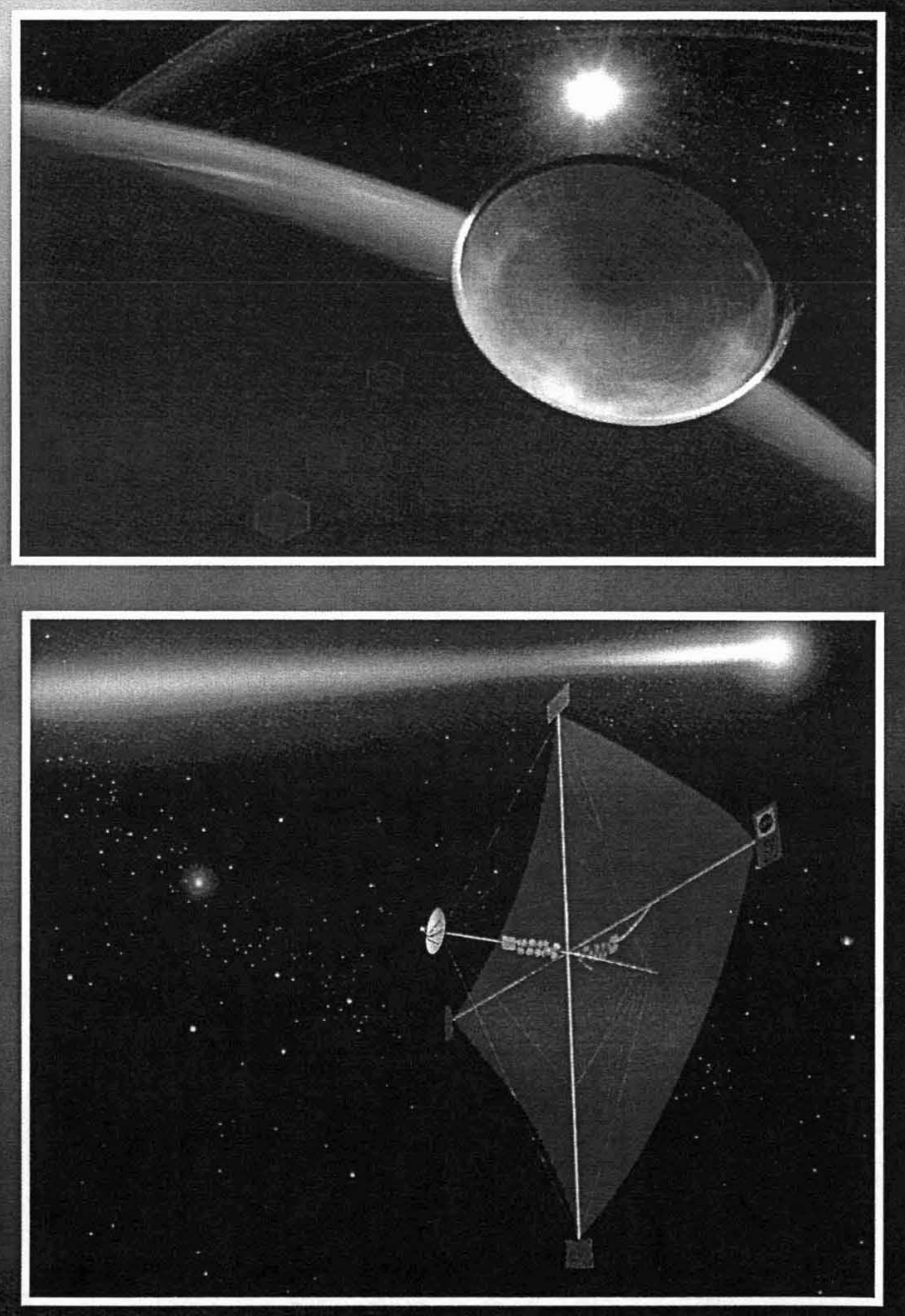


\section{In-Space Propulsion Successes}
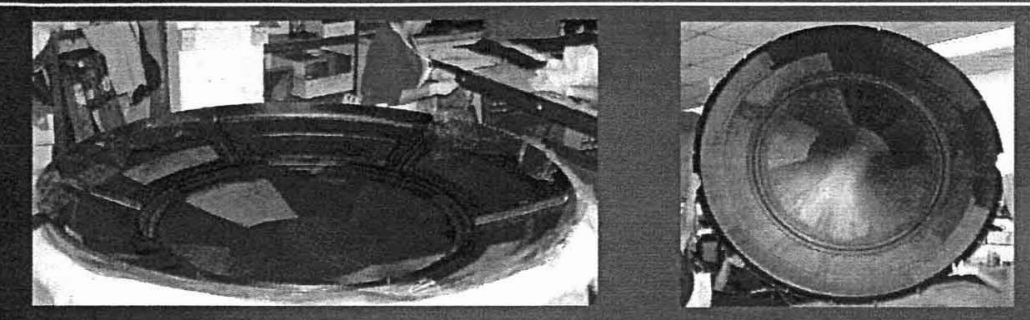

First ever, load bearing carbon-carbon requiring no substructure
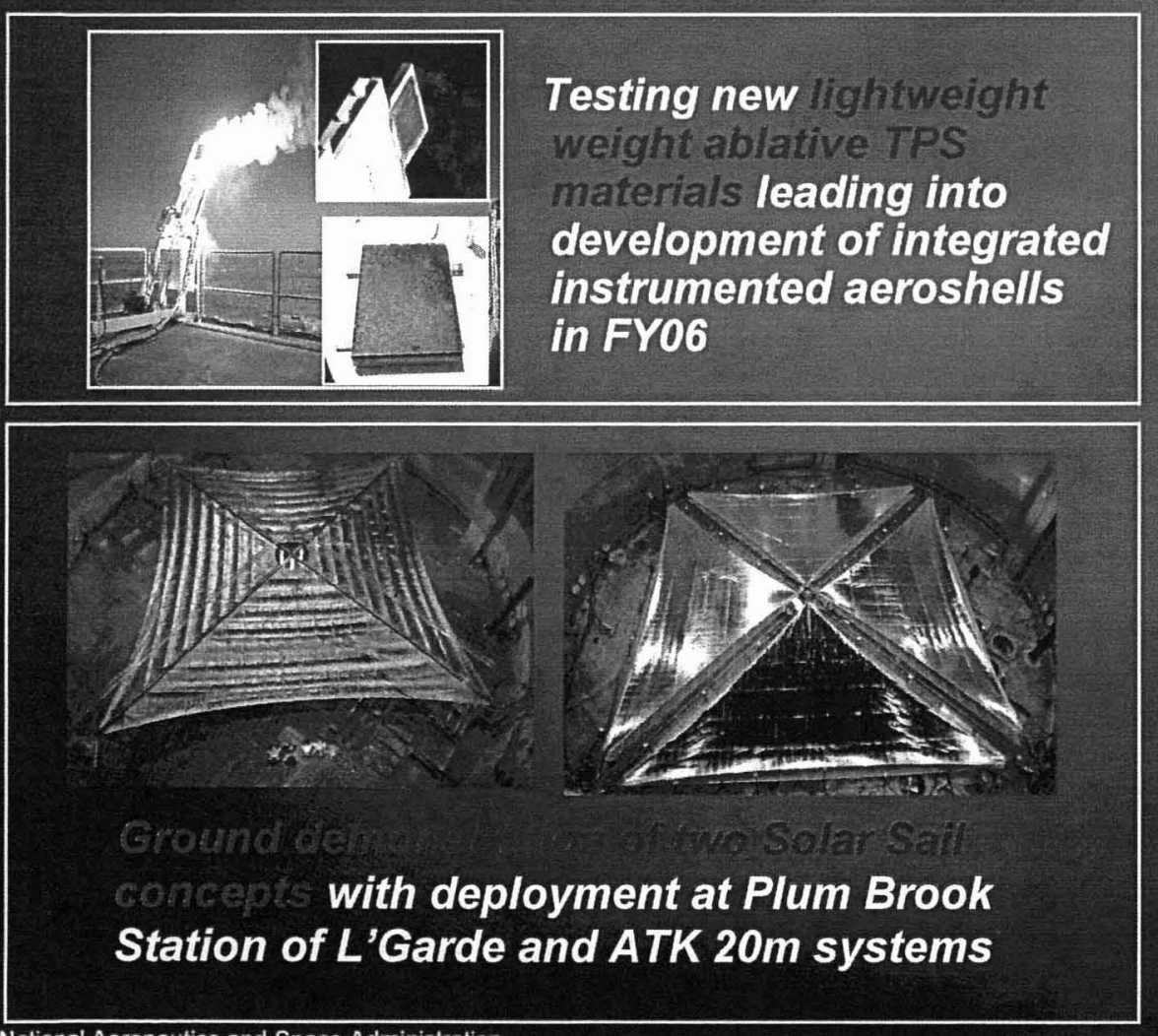

National Aeronautics and Space Administration
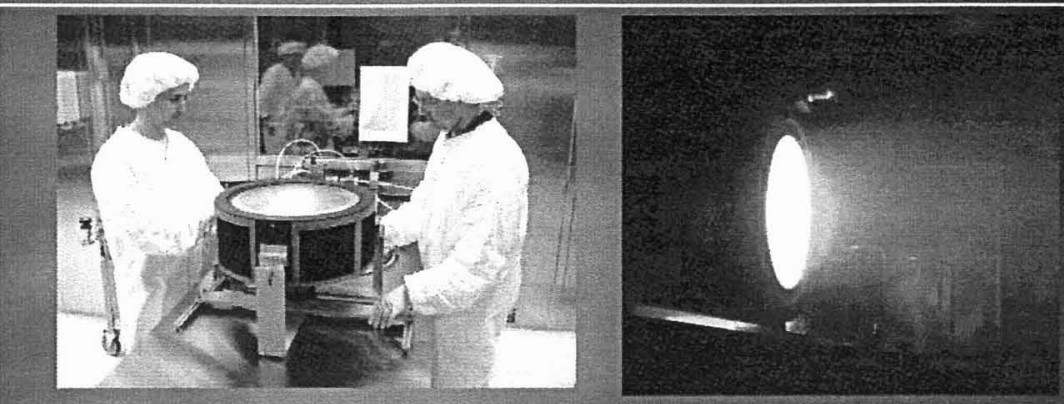

Ion thruster testing:

${ }^{*}$ NEXT engineering model past 3,000 hours *Aerojet prototype model delivered, environmental testing has begun
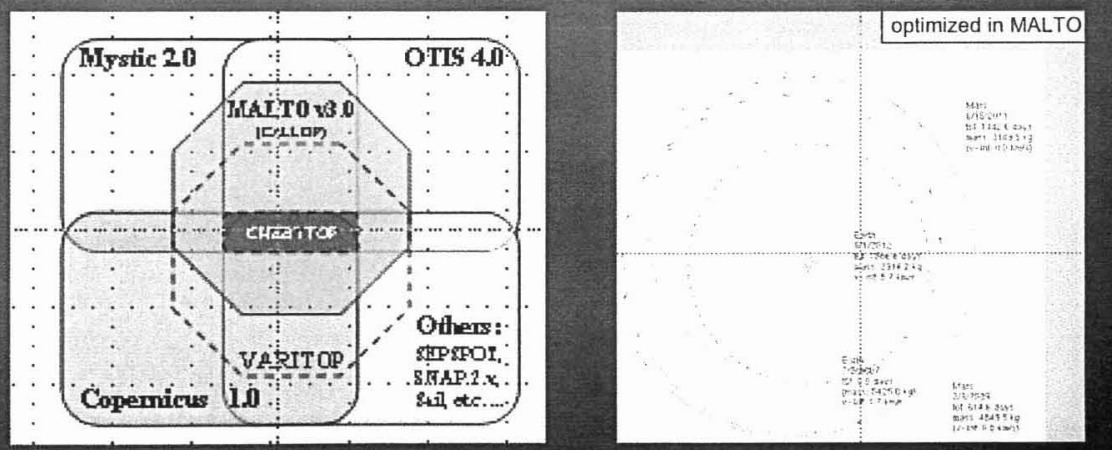

Developed set of consistent, state-of-theart - rollout 


\section{NASA Is Losing Ground To our Competitors in New Space Propulsion Technologies}

"The preservation of the role of the United States as a leader in aeronautical and space science and technology and in the application thereof..." "The preservation of the Unitred States preeminent position in aeronautics and space through research and technology developmei

The National Atcronautics and Space Act 7/29/1958

Section 102 "Declaration of Policy and Purpose Subsection d

The World is developing and fielding advanced

I. 1 propulsion technologies

JAXA's ASTRO-F Mission included secondary payloads (launched Feb. 2006):

- deployment of a $35 \mathrm{ft}$ diameter solar sail

- nanosat to be deorbited by a $300 \mathrm{ft}$ ED tether

(pictures are representative)

ESA and the Russian Federal Space Agency, launched an Inflatable

Re-entry \& Descent technology demonstrator (Oct 2005, failed).

ESA's SMART-1 explored the moon from orbit propelled by a Hall Thruster (launched Sept 2003).

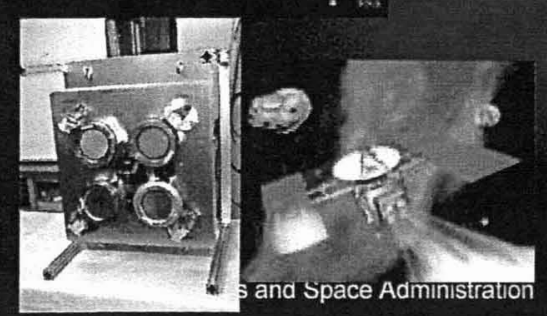

Three $(+1)$ gridded ion engines are flying on the Japanese Hayabusa mission to the asteroid Itokawa for mapping and sample return. The first application of a

microwave ion thruster in flight. (launched May 2003) 


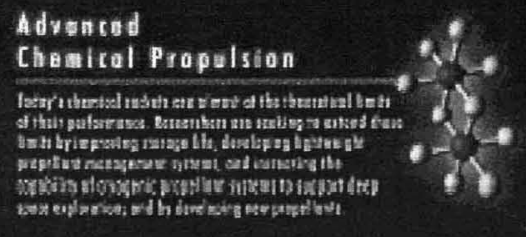

Aercicaplute

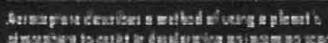

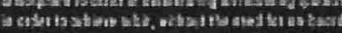

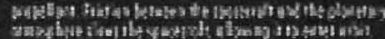

Electric Prapulsion

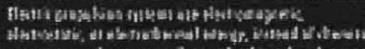

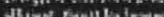

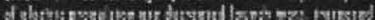

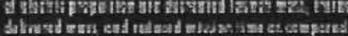
thaงe ลามอ

Solor Soil Propulsion



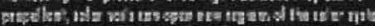

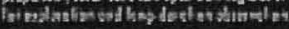

Emerging Propulsion Technologies

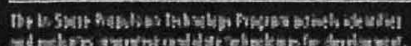

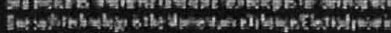

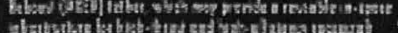

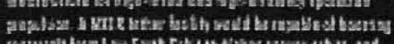

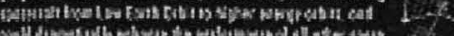



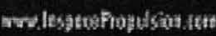

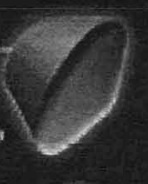

\section{0}
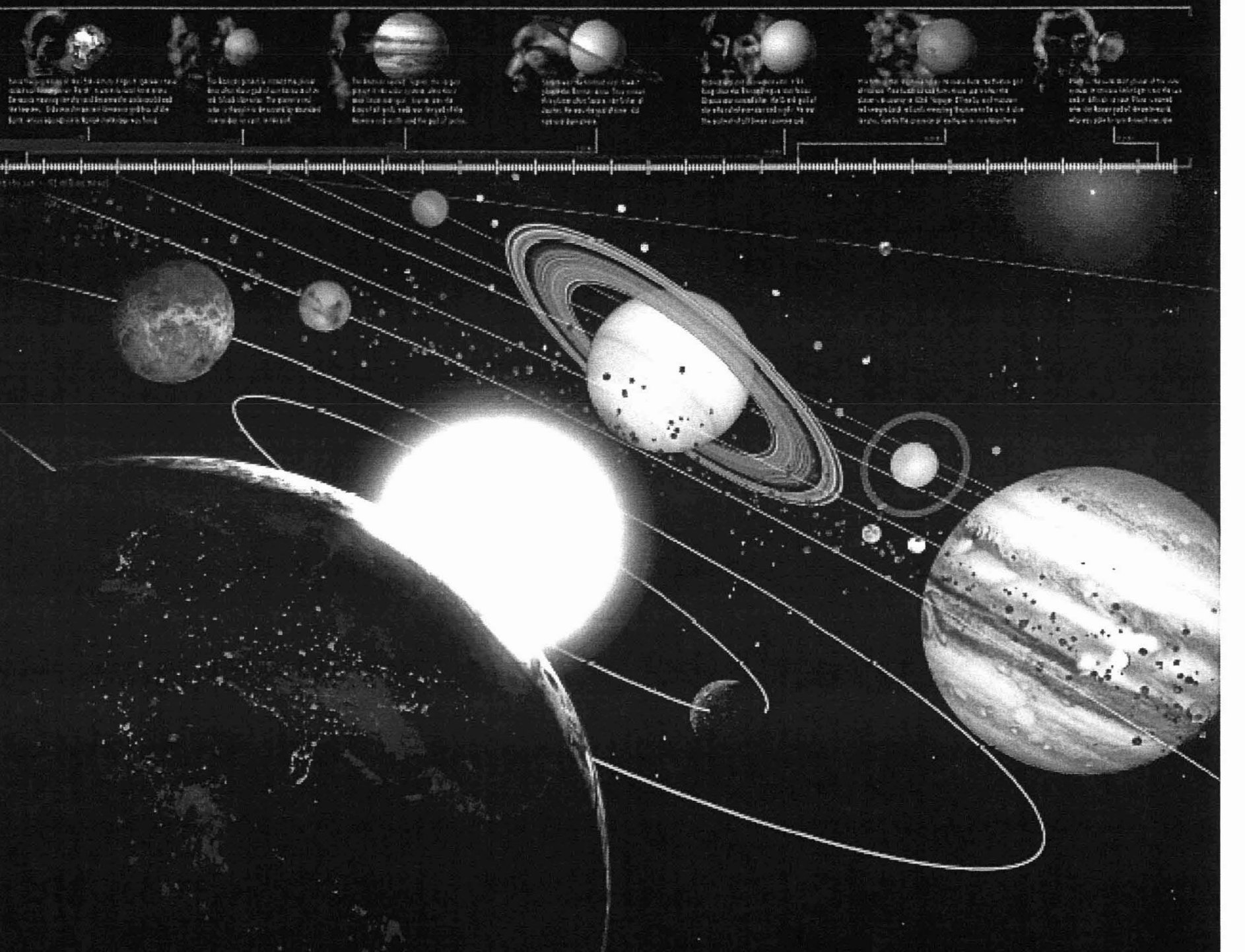

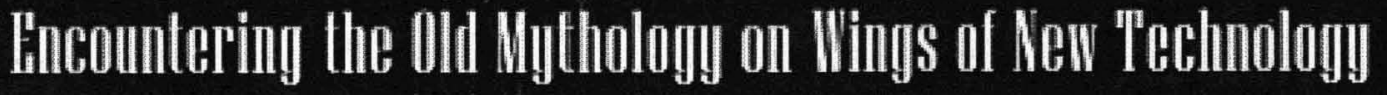




\section{For additional information on the In Space Propulsion Technology Project, please contact:}

Ms. Rae Ann Meyer

Project Manager

Phone: 256-544-7146

rae.w.meyer@nasa.gov

Mr. Randy Baggett

Deputy Project Manager

Phone: 256-544-4101

randy.m.baggett@nasa.gov 
NA 84

www nasa.gov 